\title{
Design Methodology for Three-Phase Four-Wire T-Type Inverter With Neutral Inductor
}

\author{
Li ZHANG, Haoxin YANG, Kui WANG, Yalei YUAN, Yi TANG, and Wai Kuan LOH
}

\begin{abstract}
Three-level (3L) converters have been widely used in industry for decades. Compared to the three-phase-threewire $(3 \mathrm{P} 3 \mathrm{~W}) 3 \mathrm{~L}$ inverter, the three-phase-four-wire $(3 \mathrm{P} 4 \mathrm{~W})$ one is able to supply the unbalanced loads but has to afford much larger filter inductors because the neutral wire provides a path for high-switching zero-sequence currents. To save filter inductances, a neutral inductor is proposed to insert in the neutral wire. Meanwhile, a complete design methodology is put forward to design the filter inductors and the neutral inductor. With lowfrequency zero-sequence currents flowing through the neutral wire, the three-phase load voltages might become unbalanced and/or distorted. To improve the voltage quality, a resonant controller, with the resonant frequency at fundamental output frequency $\left(f_{0}\right)$, is presented to add into the zero-sequence voltage loop for balancing load voltages; concurrently, the other resonant controller, with the resonant frequency at $3 f_{0}$, is presented to insert in the zero-sequence voltage loop or neutral current loop for mitigating voltage distortion. Finally, all of the proposed works are verified on a 3P4W T-type inverter.
\end{abstract}

Index Terms-Filter inductor, neutral inductor, neutral wire, three-level inverter, three-phase-four-wire, unbalanced load, voltage distortion.

\section{INTRODUCTION}

$\mathrm{T}$ HREE-level (3L) converters have lower voltage stress for switching devices, smaller footprint for filters, and higher power quality for ac loads, with respect to their two-level (2L) counterparts [1]-[4]. Because of higher conversion efficiency, higher power density, and lower voltage/current harmonics, $3 \mathrm{~L}$ converters have been widely used in uninterrupted power supplies [5], high-speed motor drives [6], more-electric aircrafts [7], more-electric ships [8], renewable energy generation systems [9], and etc, in the past decades.

The three-phase $3 \mathrm{~L}$ inverter in general has two configurations, namely, three-phase-three-wire- $(3 \mathrm{P} 3 \mathrm{~W})$ and three-

Manuscript received August 5, 2020; revised October 9, 2020; accepted November 17, 2020. Date of publication March 30, 2021; date of current version March 20, 2021. (Corresponding Author: Yi Tang.)

L. Zhang, H. Yang, Y. Tang, and W. K. Loh are with Nanyang Technological University, Singapore (e-mail: li-zhang@ntu.edu.sg; haoxin.yang@ntu.edu.sg; yitang@ntu.edu.sg; lohwk@ntu.edu.sg).

$\mathrm{K}$. Wang is with Department of Electrical Engineering, Tsinghua University, Beijing, China (e-mail: wangkui@tsinghua.edu.cn).

Y. Yuan is with China University of Mining and Technology, Xuzhzou, China (e-mail: n1906458h@e.ntu.edu.sg).

Digital Object Identifier 10.24295/CPSSTPEA.2021.00008 phase-four-wire- (3P4W) 3L inverter. The only difference is the neutral wire which provides the path for the zero-sequence component in load currents and thus makes the $3 \mathrm{P} 4 \mathrm{~W} 3 \mathrm{~L}$ inverter capable to supply both balanced and unbalanced ac loads [10]. Nonetheless, the neutral wire also provides the path for high-switching zero-sequence harmonic currents, leading to increased inductor current ripple. Consequently, the filter inductors in the 3P4W $3 \mathrm{~L}$ inverter are much higher than those in the $3 \mathrm{P} 3 \mathrm{~W} 3 \mathrm{~L}$ inverter, resulting in degraded power density. To solve this problem, this paper explores the way of reducing the total filter inductance in the 3P4W 3L inverter.

The total filter inductance is not exclusively increased in the 3P4W 3L inverter with respect to the 3P3W counterpart, but also increased in the $3 \mathrm{P} 4 \mathrm{~W} 2 \mathrm{~L}$ inverter in comparison with the 3P $3 \mathrm{~W}$ one. To cope with this problem, an inductor is inserted in the neutral wire of the 3P4W 2L inverter [11], such that the inductor current ripple can remain the same with lower filter inductors. Unfortunately, however, the neutral inductor in [11] is not specifically designed, let alone has a rigorous design methodology. To fill the gap, a design flow is proposed in [12] for evaluating the minimum required filter inductance in the 3P4W 2L inverter with split dc-link capacitors. In doing so, the filter inductors as well as the neutral inductor can be optimally designed. The neutral inductor has also been reported to insert in other $2 \mathrm{~L}$ inverter topologies. In [13], neutral inductor is proposed to add in the three-phase four-leg $2 \mathrm{~L}$ inverter. Nonetheless, this neutral inductor is aimed for reducing the voltage pulsation at the neutral point rather than saving filter inductors. In [14], neutral inductor is introduced in the active split dc-bus four-leg inverter. Different from the one in [11], however, this inductor is used for reducing the current ripple in the neutral module.

Inspired by [11], this paper proposes to insert an inductor in the neutral wire of the $3 \mathrm{P} 4 \mathrm{~W} 3 \mathrm{~L}$ inverter for reducing the size and volume of the filter inductors. Please note that the minimum required filter inductance is determined by the maximum volt-second of the inductor voltage and the expected inductor current ripple, over a line cycle, and that the volt-second of the inductor voltage is further determined by the inverter switching state. As the switching state of the $3 \mathrm{~L}$ inverter is far more complex than that of the $2 \mathrm{~L}$ inverter, the derived formulas in [12] are no longer valid for the 3P4W $3 \mathrm{~L}$ inverter. For the purpose of providing a guidance to design the filter inductors and the neutral inductor in the $3 \mathrm{P} 4 \mathrm{~W} 3 \mathrm{~L}$ 


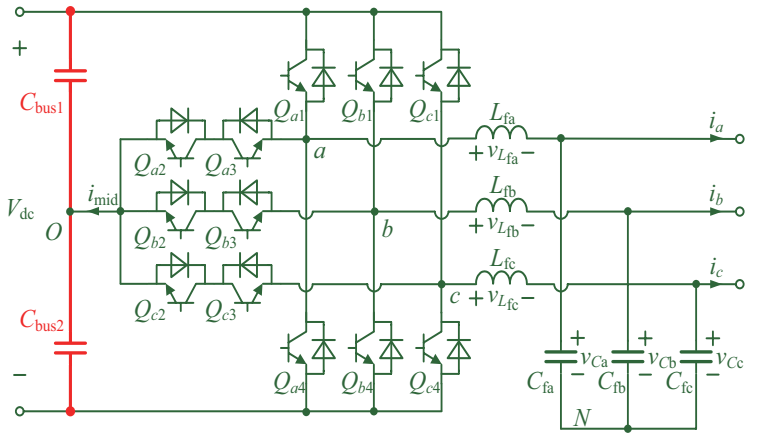

(a)

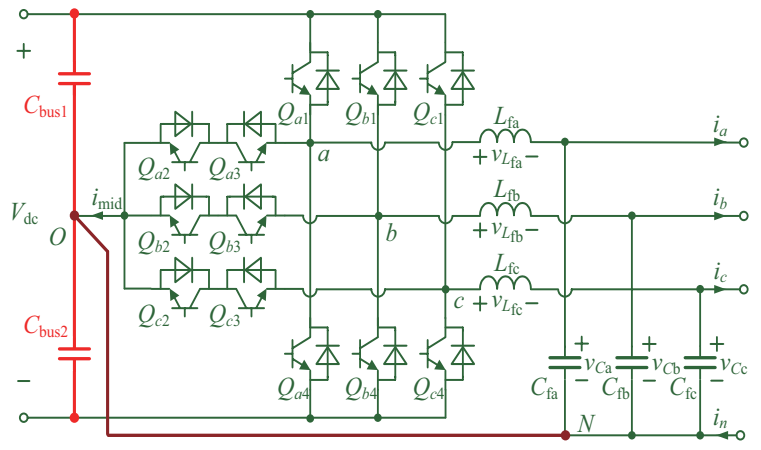

(b)

Fig. 1. Topology of (a) 3P3W T-type inverter and (b) 3P4W T-type inverter.

inverter, this paper will also show a complete methodology for inductance derivation and demonstrate how the inserted neutral inductor benefits the reduction for filter inductors.

The load voltage quality is the other significant factor for judging the performance of a 3P4W 3L inverter [15]. When supplying unbalanced loads, the fundamental zerosequence current will flow through the neutral wire, inducing fundamental voltage ripples in the upper and lower dc bus capacitors, which might further produce fundamental zerosequence voltage in the three-phase load voltages and therefore make the load voltage become unbalanced. In addition to the high-frequency zero-sequence harmonic currents and the fundamental zero-sequence current, the neutral wire also provides the path for triplen harmonics, which makes it more preferable to adopt the basic level-shifted sinusoidal pulse width modulation (LS-SPWM) to modulate the $3 \mathrm{P} 4 \mathrm{~W}$ $3 \mathrm{~L}$ inverter [15]. Different from the $2 \mathrm{~L}$ inverter, upper and lower dc bus capacitors inherently carry third-order voltage ripples with the LS-SPWM [16]. This might result in thirdorder harmonic current circulating along the L-C filter and the neutral wire, making the three-phase load voltages become distorted. For having a good voltage quality, this paper will also discuss the zero-sequence voltage control, so as to mitigate the potential voltage unbalance and distortion issue for both balanced and unbalanced loads.

The rest of the paper is organized as follows. Section II briefly illustrates the reason for why 3P4W 3L inverter needs larger filter inductors and proposes to insert an inductor in the

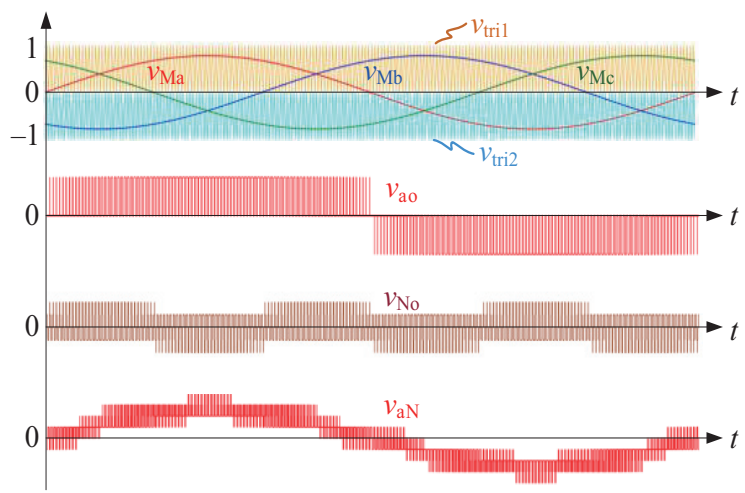

(a)

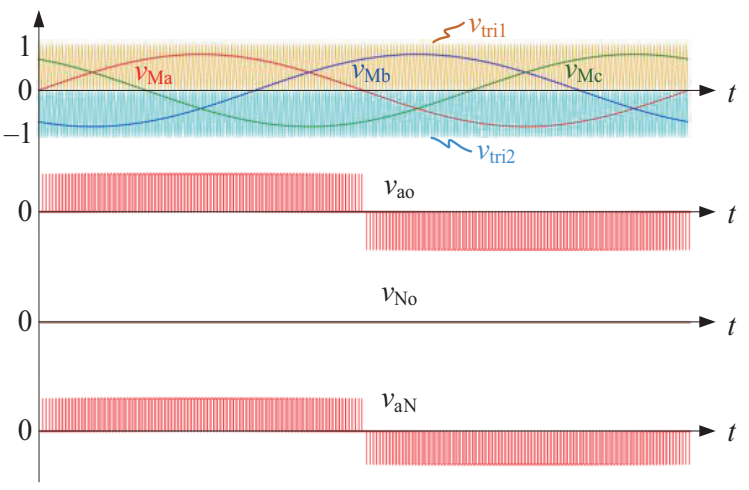

(b)

Fig. 2. Key waveforms of (a) 3P3W T-type inverter and (b) 3P4W T-type inverter with level-shifted SPWM.

neutral wire. Thereafter, Section III proposes the methodology for designing the filter inductors and the neutral inductor, and also shows the benefit of the neutral inductor in reducing the minimum required filter inductance. To eliminate the potential unbalancing and distortion in the load voltage, dedicated zero-sequence voltage control is discussed in Section IV. The experimental results are shown in Section V. Finally, Section VI concludes this paper.

\section{RoOT OF InCREASED INDUCTOR CURRENT RIPPLE IN Three-Phase-Four-Wire T-Type InVerter}

Figs. 1(a) and (b) respectively show the topology of the basic 3P3W and 3P4W T-type inverter, where $C_{\text {bus } 1}$ and $C_{\text {bus } 2}$ form the split capacitor leg, $Q_{x 1}-Q_{x 4}(x=\mathrm{a}, \mathrm{b}, \mathrm{c})$ form three phase legs, and $L_{\mathrm{f} x}$ and $C_{\mathrm{f} x}$ form the three-phase L-C filter. The power stage of these two topologies is quite the same. The only difference is the neutral wire in the $3 \mathrm{P} 4 \mathrm{~W}$ inverter which connects from the neutral point, i.e., $N$ to the midpoint of the split capacitor leg $O$. For the ease of illustration, $O$ is hereon seen as a reference point.

Because the neutral wire provides a path for the zerosequence currents, the basic LS-SPWM is adopted to modulate the $3 \mathrm{P} 4 \mathrm{~W}$ inverter [15]. To show the differences in the working principle, Figs. 2 (a) and (b) respectively show the key waveforms of the 3P3W and 3P4W T-type inverter with 


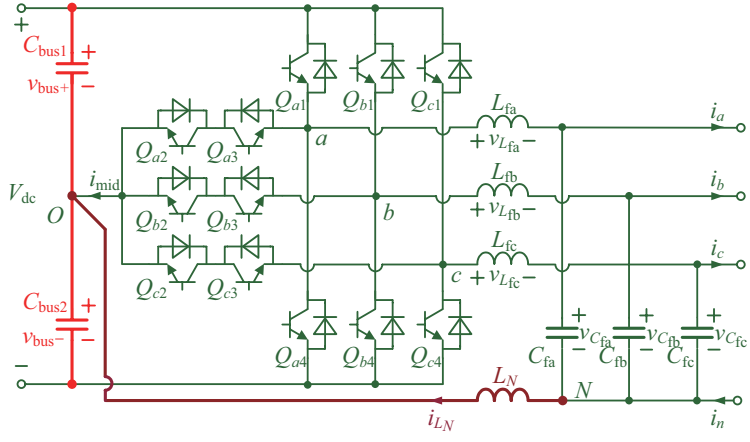

Fig. 3. Topology of 3P4W T-type inverter with neutral inductor.

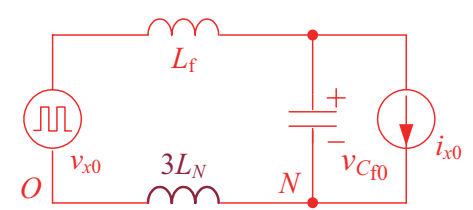

Fig. 4. Zero-sequence circuit of the 3P4W T-type inverter with neutral inductor.

LS-SPWM, where $v_{\text {tri1 }}$ and $v_{\text {tri2 }}$ are two level-shifted unitymagnitude triangle carrier waveforms; $v_{\mathrm{Ma}}, v_{\mathrm{Mb}}$, and $v_{\mathrm{Mc}}$ are respectively the modulation waveform for each phase leg; $v_{\mathrm{ao}}$ is the phase-leg-a output voltage, $v_{\text {No }}$ is the neutral-point voltage, and $v_{\mathrm{aN}}$ is the voltage difference of $v_{\mathrm{ao}}$ and $v_{\mathrm{No}}$. For the T-type inverter, $v_{\mathrm{Mx}}(x=\mathrm{a}, \mathrm{b}, \mathrm{c})$ is compared with $v_{\text {tril }}$ to generate the gate signals for $Q_{x 1}$ and $Q_{x 2}$, whereas compared with $v_{\text {tri2 }}$ to generate the gate signals for $Q_{x 3}$ and $Q_{x 4}$ [15]. When $v_{\mathrm{Mx}}>0, Q_{x 1}$ and $Q_{x 2}$ conduct in a complementary manner, $Q_{x 3}$ is always $\mathrm{ON}$, and $Q_{x 4}$ is always OFF. When $v_{\mathrm{M} x}<0, Q_{x 1}$ is always OFF, $Q_{x 2}$ is always $\mathrm{ON}, Q_{x 3}$ and $Q_{x 4}$ conduct in a complementary manner.

Seen from Fig. 2, $v_{\text {No }}$ pulsates at switching frequency in the 3P3W T-type inverter, but remains at 0 in the 3P4W T-type inverter. Since $v_{\text {No }}$ in the $3 \mathrm{P} 3 \mathrm{~W}$ T-type inverter equals to the common-mode voltage harmonics in $v_{x 0}$, the common-mode voltage components in $v_{\mathrm{ao}}$ can be fully cancelled by $v_{\mathrm{No}}$, making $v_{\mathrm{aN}}$ free of triplen-sideband harmonics. By contrast, the commonmode components in $v_{\mathrm{ao}}$ of the 3P4W T-type inverter cannot be cancelled, resulting in high-frequency harmonic currents circulating through the three-phase LC filter and the neutral wire. With the same filter inductances, therefore, the filter inductor current ripple in 3P4W T-type inverter will be higher.

Increasing the impedance of the zero-sequence current path can help reduce the filter inductor current ripple in the $3 \mathrm{P} 4 \mathrm{~W}$ inverter. To obtain this objective, a neutral inductor, i.e., $L_{N}$ is proposed to insert into the neutral wire, as shown in Fig. 3. In doing so, the zero-sequence circuit of the power stage can be illustrated as presented in Fig. 4, where $L_{\mathrm{f} x}=L_{\mathrm{f}}, v_{x 0}=\left(\sum v_{x 0}\right)$ $/ 3$ is the common-mode voltage of $v_{x \mathrm{o}}, v_{C \mathrm{f} 0}=\left(\sum v_{\mathrm{ff}_{\mathrm{f}}}\right) / 3$ is the common-mode voltage of $v_{C_{\mathrm{fx}}}$, and $i_{x 0}=\left(\sum i_{x}\right) / 3$ is the commonmode current of load currents. According to Fig. $4, v_{N o}$ is

$$
v_{N o}=\frac{3 L_{N}}{3 L_{N}+L_{\mathrm{f}}} \cdot \frac{1}{3} \sum_{x=a, b, c} v_{x o}=\frac{3 L_{N}}{3 L_{N}+L_{\mathrm{f}}} v_{x 0} \triangleq k v_{x 0}
$$

Particularly, $k=1$ if $L_{N}=\infty$, transforming Fig. 3 into the basic 3P3W T-type inverter, as shown in Fig. 1(a); and $k=0$ if $L_{N}=$ 0, transforming Fig. 3 into the basic 3P4W T-type inverter, as shown in Fig. 1(b). Obviously, the insertion of $L_{N}$ makes the common-mode voltage harmonics in $v_{x o}$ partly cancelled by $v_{N o}$.

\section{Design Methodology for Filter Inductors AND NeUTRAL INDUCTOR}

The minimum required inductance of $L_{\mathrm{f} x}$, i.e., $L_{\mathrm{fmin}}$, is concurrently determined by the maximum volt-second of $v_{L_{\mathrm{fx}}}$ and the expected inductor current ripple, over a line cycle. Taking the derivation of $L_{\text {fmin }}$ for phase $a$ as an example, this section illustrates the methodology of designing $L_{\mathrm{f} x}$ and $L_{N}$. Because of the symmetrical characterization, it is only necessary to analyze the voltages and currents of phase $a$ in the first quarter of a line cycle, i.e., $\omega t \in[0, \pi / 2]$, for deriving the closed-form formulas.

The voltage across $L_{\mathrm{fa}}$, i.e., $v_{L_{\mathrm{fa}}}$, equals to the difference of $v_{\mathrm{aN}}$ and $v_{\mathrm{Ca}}$, of which, $v_{\mathrm{Ca}}$ can be assumed constant within a switching cycle because the switching frequency is far higher than the fundamental frequency, whereas $v_{\mathrm{aN}}$ pulsates at switching frequency and varies with the inverter switching state which is further decided by the intersection sequence of modulation waveforms and carrier waveforms.

Without the loss of generality, we assume $v_{\mathrm{Ma}}, v_{\mathrm{Mb}}$, and $v_{\mathrm{Mc}}$ are written as

$$
\left\{\begin{array}{l}
v_{\mathrm{Ma}}=M \sin \omega t \\
v_{\mathrm{Mb}}=M \sin (\omega t-2 \pi / 3) \\
v_{\mathrm{Mc}}=M \sin (\omega t+2 \pi / 3)
\end{array}\right.
$$

where $M$ is the modulation index and $\omega$ is the fundamental angular frequency. Since $v_{\mathrm{Ma}}$ equals to $v_{\mathrm{Mc}}$ at $\pi / 6$, the curve of $v_{\mathrm{Ma}}$ will always cross with that of $v_{\mathrm{Mc}}$ at $\pi / 6$. Similarly, $(1+$ $\left.v_{\mathrm{Mb}}\right)$ equals to $\left(1+v_{\mathrm{Mc}}\right)$ at $\pi / 2$, hence, the curve of $\left(1+v_{\mathrm{Mb}}\right)$ will always cross with that of $\left(1+v_{\mathrm{Mc}}\right)$ at $\pi / 2$. Let $v_{\mathrm{Ma}}=1+v_{\mathrm{Mb}}$, we have

$$
\begin{aligned}
& \alpha_{1}=\pi / 3-\arccos [1 /(\sqrt{3} M)], M \in[\sqrt{3} / 3,1] \\
& \alpha_{2}=\pi / 3+\arccos [1 /(\sqrt{3} M)], M \in[\sqrt{3} / 3,1]
\end{aligned}
$$

Obviously, $\alpha_{1}<\pi / 2$. Nonetheless, $\alpha_{2} \leq \pi / 2$ when $\sqrt{3} / 3 \leq M \leq$ $2 / 3$, whereas $\alpha_{2}>\pi / 2$ when $2 / 3<M \leq 1$. Let $v_{\mathrm{Mc}}=1+v_{\mathrm{Mb}}$, we have

$$
\alpha_{3}=\arccos [1 /(\sqrt{3} M)], M \in[\sqrt{3} / 3,1]
$$

Obviously, $\alpha_{3}<\pi / 2$. Let $v_{\mathrm{Ma}}=1+v_{\mathrm{Mc}}$, we have

$$
\alpha_{4}=2 \pi / 3-\arccos [1 /(\sqrt{3} M)], M \in[\sqrt{3} / 3,1
$$

According to (6), $\alpha_{4} \leq \pi / 2$ when $2 / 3 \leq M \leq 1$, whereas $\alpha_{4}>\pi / 2$ when $\sqrt{3} / 3 \leq M<2 / 3$. 


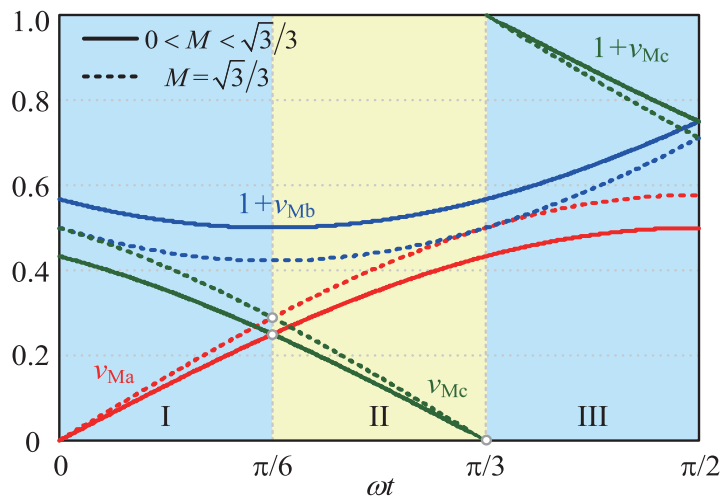

(a)

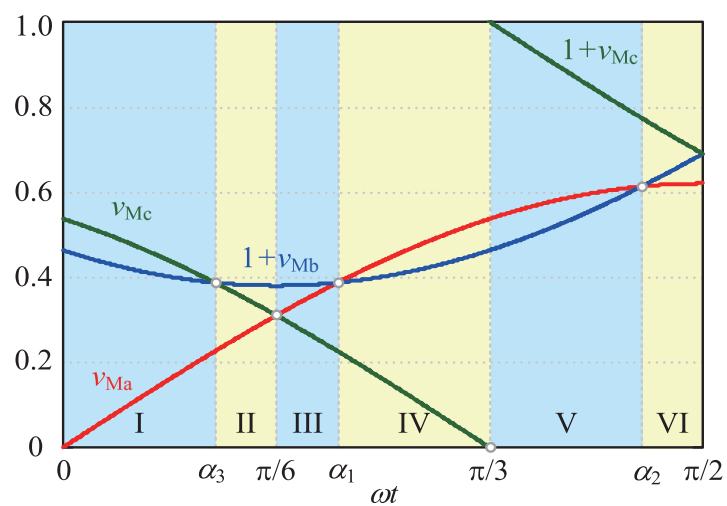

(b)

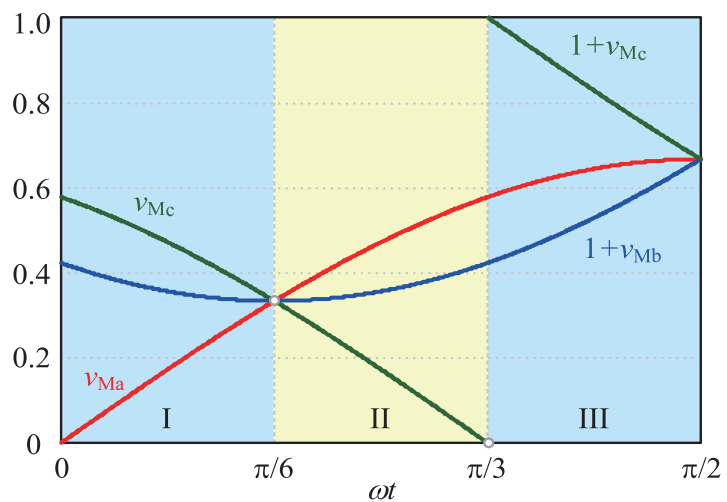

(c)

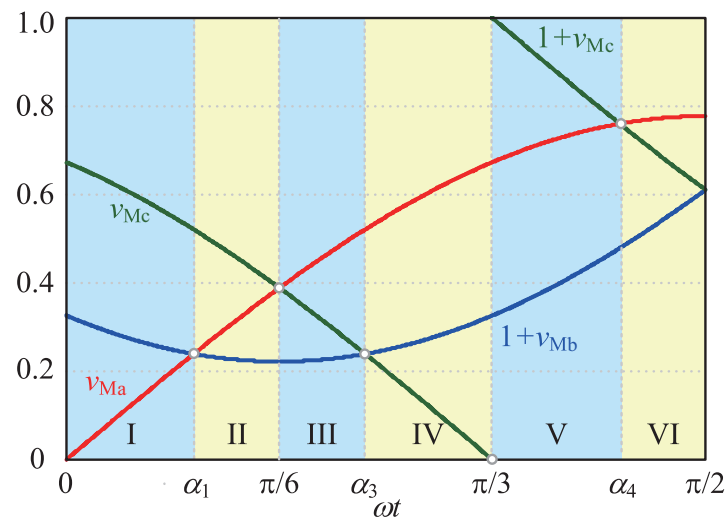

(d)

Fig. 5. Plots of $v_{\mathrm{M} x}$ and $1+v_{\mathrm{M} x}$ in the first quarter of a line cycle. (a) $0<M \leq$ $\sqrt{3} / 3$. (b) $\sqrt{3} / 3<M<2 / 3$. (c) $M=2 / 3$. (d) $2 / 3<M<1$.
TABLE I

Intersection Sequence of Modulation and CARrier WaVeforms

\begin{tabular}{lcl}
\hline \hline$M$ & $\omega t$ & Sequence \\
\hline & $(0, \pi / 6]$ & $\mathrm{B} \rightarrow \mathrm{C} \rightarrow \mathrm{A}$ \\
{$[0, \sqrt{3} / 3]$} & $(\pi / 6, \pi / 3]$ & $\mathrm{B} \rightarrow \mathrm{A} \rightarrow \mathrm{C}$ \\
& $(\pi / 3, \pi / 2)$ & $\mathrm{C} \rightarrow \mathrm{B} \rightarrow \mathrm{A}$ \\
\hline & $\left(0, \alpha_{3}\right]$ & $\mathrm{C} \rightarrow \mathrm{B} \rightarrow \mathrm{A}$ \\
& $\left(\alpha_{3}, \pi / 6\right]$ & $\mathrm{B} \rightarrow \mathrm{C} \rightarrow \mathrm{A}$ \\
$(\sqrt{3} / 3,2 / 3]$ & $\left(\pi / 6, \alpha_{1}\right]$ & $\mathrm{B} \rightarrow \mathrm{A} \rightarrow \mathrm{C}$ \\
& $\left(\alpha_{1}, \pi / 3\right]$ & $\mathrm{A} \rightarrow \mathrm{B} \rightarrow \mathrm{C}$ \\
& $\left(\pi / 3, \alpha_{2}\right]$ & $\mathrm{C} \rightarrow \mathrm{A} \rightarrow \mathrm{B}$ \\
& $\left(\alpha_{2}, \pi / 2\right)$ & $\mathrm{C} \rightarrow \mathrm{B} \rightarrow \mathrm{A}$ \\
\hline & $(0, \pi / 6]$ & $\mathrm{C} \rightarrow \mathrm{B} \rightarrow \mathrm{A}$ \\
$2 / 3$ & $(\pi / 6, \pi / 3]$ & $\mathrm{A} \rightarrow \mathrm{B} \rightarrow \mathrm{C}$ \\
& $(\pi / 3, \pi / 2)$ & $\mathrm{C} \rightarrow \mathrm{A} \rightarrow \mathrm{B}$ \\
\hline & $\left(0, \alpha_{1}\right]$ & $\mathrm{C} \rightarrow \mathrm{B} \rightarrow \mathrm{A}$ \\
& $\left(\alpha_{1}, \pi / 6\right]$ & $\mathrm{C} \rightarrow \mathrm{A} \rightarrow \mathrm{B}$ \\
& $\left(\pi / 6, \alpha_{3}\right]$ & $\mathrm{A} \rightarrow \mathrm{C} \rightarrow \mathrm{B}$ \\
& $\left(\alpha_{3}, \pi / 3\right]$ & $\mathrm{A} \rightarrow \mathrm{B} \rightarrow \mathrm{C}$ \\
$(2 / 3,1]$ & $\left(\pi / 3, \alpha_{4}\right]$ & $\mathrm{C} \rightarrow \mathrm{A} \rightarrow \mathrm{B}$ \\
& $\left(\alpha_{4}, \pi / 2\right)$ & $\mathrm{A} \rightarrow \mathrm{C} \rightarrow \mathrm{B}$ \\
\hline \hline
\end{tabular}

Fig. 5 plots the curves of $v_{\mathrm{M} x}$ and $\left(1+v_{\mathrm{M} x}\right)$ in the range of 0 to 1 , against $\omega t \in[0, \pi / 2]$. In accordance with Fig. 5, Table I summarized all the possible cases for intersection sequence of modulation waveforms and carrier waveforms:

1)When $0 \leq M<\sqrt{3} / 3,\left(1+v_{\mathrm{Mb}}\right)$ has no crossing points with $v_{\mathrm{Ma}}$ and $v_{\mathrm{Mc}}$, as shown with the solid line in Fig. 5(a). In this case, $v_{\mathrm{Mb}}$ is the first one intersecting with the carrier waveform, $v_{\mathrm{Mc}}$ the second, and $v_{\mathrm{Ma}}$ the third when $\omega t \in[0$, $\pi / 6]$. For the ease of illustration, intersection sequence is denoted as $\mathrm{B} \rightarrow \mathrm{C} \rightarrow \mathrm{A}$. Likewise, the intersection sequence is $\mathrm{B} \rightarrow \mathrm{A} \rightarrow \mathrm{C}$ when $\omega t \in[\pi / 6, \pi / 3]$, and $\mathrm{C} \rightarrow \mathrm{B} \rightarrow \mathrm{A}$ when $\omega t \in[\pi / 3, \pi / 2]$. Specially, when $M=\sqrt{3} / 3,\left(1+v_{\mathrm{Mb}}\right)$ is tangent with $v_{\mathrm{Ma}}$ and $v_{\mathrm{Mc}}$, as shown with the dashed line in Fig. 5(a), but the intersection sequence remains the same.

2)When $\sqrt{3} / 3<M<2 / 3,\left(1+v_{\mathrm{Mb}}\right)$ crosses with $v_{\mathrm{Ma}}$ at $\alpha_{1}$ and $\alpha_{2}$, and also with $v_{\mathrm{Mc}}$ at $\alpha_{3}$, as shown in Fig. 5(b). In this case, the intersection sequence is $\mathrm{C} \rightarrow \mathrm{B} \rightarrow \mathrm{A}$ when $\omega t \in\left[0, \alpha_{3}\right]$, $\mathrm{B} \rightarrow \mathrm{C} \rightarrow \mathrm{A}$ when $\omega t \in\left[\alpha_{3}, \pi / 6\right], \mathrm{B} \rightarrow \mathrm{A} \rightarrow \mathrm{C}$ when $\omega t \in[\pi / 6$, $\left.\alpha_{1}\right], \mathrm{A} \rightarrow \mathrm{B} \rightarrow \mathrm{C}$ when $\omega t \in\left[\alpha_{1}, \pi / 3\right], \mathrm{C} \rightarrow \mathrm{A} \rightarrow \mathrm{B}$ when $\omega t \in\left[\pi / 3, \alpha_{2}\right]$, and $\mathrm{C} \rightarrow \mathrm{B} \rightarrow \mathrm{A}$ when $\omega t \in\left[\alpha_{2}, \pi / 2\right]$.

3)When $M=2 / 3,\left(1+v_{\mathrm{Mb}}\right), v_{\mathrm{Ma}}$ and $v_{\mathrm{Mc}}$ come cross at $\pi / 6$, while $\left(1+v_{\mathrm{Mb}}\right), v_{\mathrm{Ma}}$ and $\left(1+v_{\mathrm{Mc}}\right)$ come cross at $\pi / 2$, as shown in Fig. 5(c). In this case, the intersection sequence is $\mathrm{C} \rightarrow \mathrm{B} \rightarrow \mathrm{A}$ when $\omega t \in[0, \pi / 6], \mathrm{A} \rightarrow \mathrm{B} \rightarrow \mathrm{C}$ when $\omega t \in[\pi / 6$, $\pi / 3]$, and $\mathrm{C} \rightarrow \mathrm{A} \rightarrow \mathrm{B}$ when $\omega t \in[\pi / 3, \pi / 2]$.

4)When $2 / 3<M \leq 1, v_{\mathrm{Ma}}$ crosses with $\left(1+v_{\mathrm{Mb}}\right)$ at $\alpha_{1}$ and with $\left(1+v_{\mathrm{Mc}}\right)$ at $\alpha_{4}$, while $v_{\mathrm{Mc}}$ crosses with $\left(1+v_{\mathrm{Mb}}\right)$ at $\alpha_{3}$, as shown in Fig. 5(b). In this case, the intersection sequence is $\mathrm{C} \rightarrow \mathrm{B} \rightarrow \mathrm{A}$ when $\omega t \in\left[0, \alpha_{1}\right], \mathrm{C} \rightarrow \mathrm{A} \rightarrow \mathrm{B}$ when $\omega t \in\left[\alpha_{1}, \pi / 6\right], \mathrm{A} \rightarrow \mathrm{C} \rightarrow \mathrm{B}$ when $\omega t \in\left[\pi / 6, \alpha_{3}\right], \mathrm{A} \rightarrow \mathrm{B} \rightarrow \mathrm{C}$ when $\omega t \in\left[\alpha_{3}, \pi / 3\right], \mathrm{C} \rightarrow \mathrm{A} \rightarrow \mathrm{B}$ when $\omega t \in\left[\pi / 3, \alpha_{4}\right]$, and $\mathrm{A} \rightarrow \mathrm{C} \rightarrow \mathrm{B}$ when $\omega t \in\left[\alpha_{4}, \pi / 2\right]$

As for the three-phase T-type inverter, lower $M$ will result in higher voltage stress and lower conversion efficiency. Considering the voltage drop across the filter inductor, a margin 


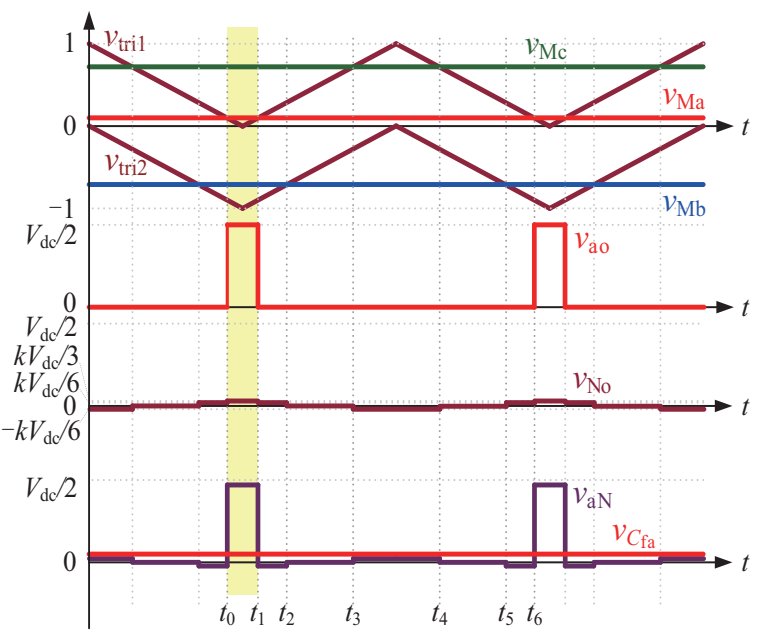

(a)

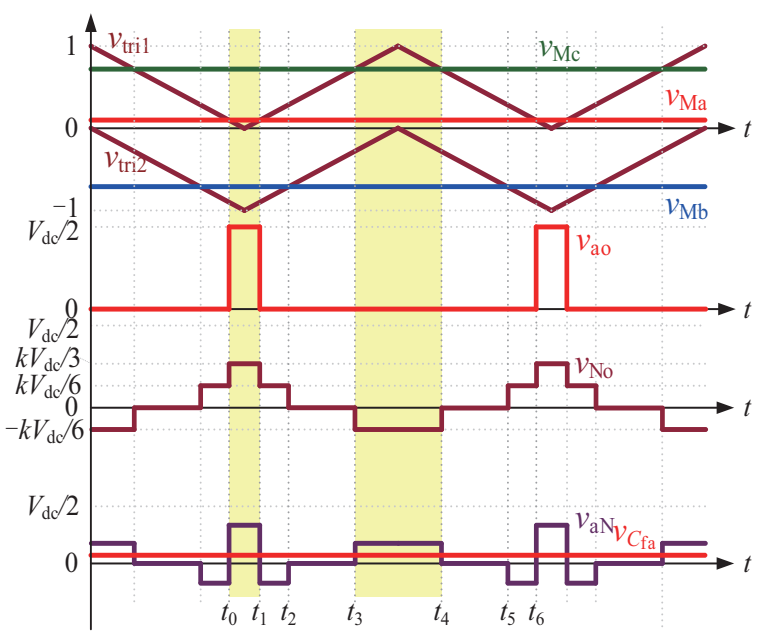

(b)

Fig. 6. Key waveforms of phase $a$ for $\omega t \in\left[0, \alpha_{1}\right]$. (a) $0 \leq k \leq 3 M \sin \omega t$ (b) $3 M \sin \omega t<k \leq 1$.

of $15 \%-25 \%$ is often reserved for $M$ to avoid overmodulation [15]. Hence, $M$ is generally higher than 0.7 in practice. So, we focus on the scenario when $2 / 3<M \leq 1$ in this paper. In the following part, the expression of $L_{\mathrm{fa}}$ will be derived for each of the subcase as highlighted in Table I. Then, $L_{\text {fmin }}$ for phase $a$ will be determined by the maximum value of $L_{\mathrm{fa}}$ over all the subcases.

Case 1: $\omega t \in\left(0, \alpha_{1}\right)$

In this case, $v_{\mathrm{Mc}}$ is the first one intersecting with the carrier waveform, $v_{\mathrm{Mb}}$ the second, and $v_{\mathrm{Ma}}$ the third, as shown in Fig. 6. $v_{\mathrm{No}}$ has four voltage levels, i.e., $k V_{\mathrm{dc}} / 3, k V_{\mathrm{dc}} / 6,0$, and $-k V_{\mathrm{dc}} / 6$. Accordingly, $v_{\mathrm{aN}}$ also has four voltage levels, i.e., $(1 / 2-k / 3)$ $V_{\mathrm{dc}},-k V_{\mathrm{dc}} / 6,0$, and $k V_{\mathrm{dc}} / 6$.

When $\omega t \in\left(0, \alpha_{1}\right), v_{C \mathrm{fa}}\left(=V_{\mathrm{dc}} v_{\mathrm{Ma}} / 2\right) \in\left(0, V_{\mathrm{dc}} / 6\right)$. As $-k V_{\mathrm{dc}} / 6$ $\leq 0$ and $V_{\mathrm{dc}} / 6 \leq(1 / 2-k / 3) V_{\mathrm{dc}} \leq V_{\mathrm{dc}} / 2$, we have $-k V_{\mathrm{dc}} / 6 \leq 0$ $<v_{C_{\mathrm{fa}}}<(1 / 2-k / 3) V_{\mathrm{dc}}$. Hence, $i_{L_{\mathrm{a}}}$ increases when $t \in\left[t_{0}, t_{1}\right]$, whereas decreases when $t \in\left[t_{1}, t_{3}\right] \cup\left[t_{4}, t_{5}\right]$. So,

1) If $0 \leq k<3 M \sin \omega t$, we have $v_{C \mathrm{fa}}>k V_{\mathrm{dc}} / 6$. Hence, $i_{L_{\mathrm{a}}}$ also decreases when $t \in\left[t_{3}, t_{4}\right]$. If $k=3 M \sin \omega t$, then $v_{C_{\mathrm{fa}}}=k V_{\mathrm{dc}} / 6$, making $i_{L_{\mathrm{a}}}$ remain constant. Because $i_{L_{\mathrm{a}}}$ only increases within $\left[t_{0}, t_{1}\right]$ when $0 \leq k \leq 3 M \sin \omega t$, the current ripple of $i_{L_{\mathrm{a}}}$ will be determined by the volt-second of $v_{L_{\mathrm{a}}}\left(=v_{\mathrm{aN}}-v_{\mathrm{Cfa}_{\mathrm{a}}}\right)$ within $\left[t_{0}\right.$, $t_{1}$ ], as highlighted in Fig. 6(a). Defining $\Delta I_{L}$ as the allowed maximum inductor current ripple, the minimum required inductance will be

$$
L_{\mathrm{f} 11}=\frac{1}{\Delta I_{L}}\left(1-\frac{2}{3} k-v_{\mathrm{Ma}}\right) \frac{V_{\mathrm{dc}}}{2} v_{\mathrm{Ma}} T_{\mathrm{s}}
$$

where $T_{\mathrm{s}}$ is the period of one switching cycle.

2) If $k>3 M \sin \omega t$, we have $v_{C_{\mathrm{fa}}}<k V_{\mathrm{dc}} / 6$. This way, $i_{L_{\mathrm{a}}}$ not only increases within $\left[t_{0}, t_{1}\right]$ but also within $\left[t_{3}, t_{4}\right]$, so that the current ripple of $i_{L_{\mathrm{a}}}$ within one switching cycle will be determined by the higher volt-second of $v_{L_{\mathrm{a}}}$ between the one within $\left[t_{0}, t_{1}\right]$ and the one within $\left[t_{3}, t_{4}\right]$, as highlighted in Fig. 6(b). Thus, the minimum required inductance will be

$$
L_{\mathrm{f} 12}=\max \left\{L_{\mathrm{f}_{11}}, \frac{1}{\Delta I_{L}}\left(\frac{1}{3} k-v_{\mathrm{Ma}}\right) \frac{V_{\mathrm{dc}}}{2}\left(1-v_{\mathrm{Mc}}\right) T_{\mathrm{s}}\right\}
$$

Case 2: $\omega t \in\left(\alpha_{1}, \pi / 6\right)$

In this case, $v_{\mathrm{Mc}}$ is the first one intersecting with the carrier waveform, $v_{\mathrm{Ma}}$ the second, and $v_{\mathrm{Mb}}$ the third, as shown in Fig. 7. $v_{\mathrm{No}}$ has four voltage levels, i.e., $k V_{\mathrm{dc}} / 3, k V_{\mathrm{dc}} / 6,0$, and $-k V_{\mathrm{dc}} / 6$. Accordingly, $v_{\mathrm{aN}}$ also has four voltage levels, i.e., $(1 / 2-k / 3)$ $V_{\mathrm{dc}},(1 / 2-k / 6) V_{\mathrm{dc}}, 0$, and $k V_{\mathrm{dc}} / 6$.

For $\omega t \in\left(\alpha_{1}, \pi / 6\right), v_{\mathrm{C}_{\mathrm{fa}}}\left(=V_{\mathrm{dc}} v_{\mathrm{Ma}} / 2\right) \in\left(0, V_{\mathrm{dc}} / 4\right)$. Since $V_{\mathrm{dc}} / 3 \leq$ $(1 / 2-k / 6) V_{\mathrm{dc}} \leq V_{\mathrm{dc}} / 2$, we have $(1 / 2-k / 6) V_{\mathrm{dc}}>v_{C \mathrm{fa}}>0$. When $\omega t$ $<\beta=\arcsin (1 /(3 M))$, we have $v_{C_{\mathrm{fa}}}<V_{\mathrm{dc}} / 6$. Further, $v_{\mathrm{Ca}_{\mathrm{fa}}}<k V_{\mathrm{dc}} / 6$ if $3 M \sin \omega t<k \leq 1$, whereas $v_{\mathrm{Cfa}}>k V_{\mathrm{dc}} / 6$ if $0 \leq k<3 M \sin \omega t$. Therefore,

1) When $\omega t \leq \beta$ and $0 \leq k<3 M \sin \omega t$, we have $0<k V_{\mathrm{dc}} / 6<v_{C \mathrm{fa}}$ $\leq(1 / 2-k / 3) V_{\mathrm{dc}} \leq(1 / 2-k / 6) V_{\mathrm{dc}}$. This way, $i_{L_{\mathrm{a}}}$ only increases within $\left[t_{0}, t_{3}\right]$, as highlighted in Fig. 7(a). Thus, the minimum required inductance will be

$$
\begin{aligned}
L_{\mathrm{f} 21}= & \frac{1}{\Delta I_{L}}\left(1-\frac{k}{3}-v_{\mathrm{Ma}}\right) \frac{V_{\mathrm{dc}}}{2}\left(v_{\mathrm{Ma}}-v_{\mathrm{Mb}}-1\right) T_{\mathrm{s}} \\
& +\frac{1}{\Delta I_{L}}\left(1-\frac{2}{3} k-v_{\mathrm{Ma}}\right) \frac{V_{\mathrm{dc}}}{2}\left(1+v_{\mathrm{Mb}}\right) T_{\mathrm{s}}
\end{aligned}
$$

2) When $\omega t \leq \beta$ and $3 M \sin \omega t<k \leq 1$, we have $0<v_{C \mathrm{fa}}<$ $k V_{\mathrm{dc}} / 6 \leq(1 / 2-k / 3) V_{\mathrm{dc}} \leq(1 / 2-k / 6) V_{\mathrm{dc}}$. Hence, $i_{L_{\mathrm{a}}}$ not only increases within $\left[t_{0}, t_{3}\right]$ but also within $\left[t_{4}, t_{5}\right]$. In this manner, the minimum required inductance will be

$L_{\mathrm{f} 22}=\max \left\{L_{\mathrm{f} 21}, \frac{1}{\Delta I_{L}}\left(\frac{1}{3} k-v_{\mathrm{Ma}}\right) \frac{V_{\mathrm{dc}}}{2}\left(1-v_{\mathrm{Mc}}\right) T_{\mathrm{s}}\right\}$

When $\omega t>\beta$, we have $v_{C_{\mathrm{fa}}}>V_{\mathrm{dc}} / 6$. Thus, $v_{C_{\mathrm{fa}}}>k V_{\mathrm{dc}} / 6$. This manner, $i_{L_{\mathrm{a}}}$ always decreases from $t_{3}$ till $t_{6}$ no matter $v_{C_{\mathrm{fa}}}$ is higher than $(1 / 2-k / 3) V_{\mathrm{dc}}$ or not, as highlighted in Fig. 7(c). In this case, the minimum required inductance will be 


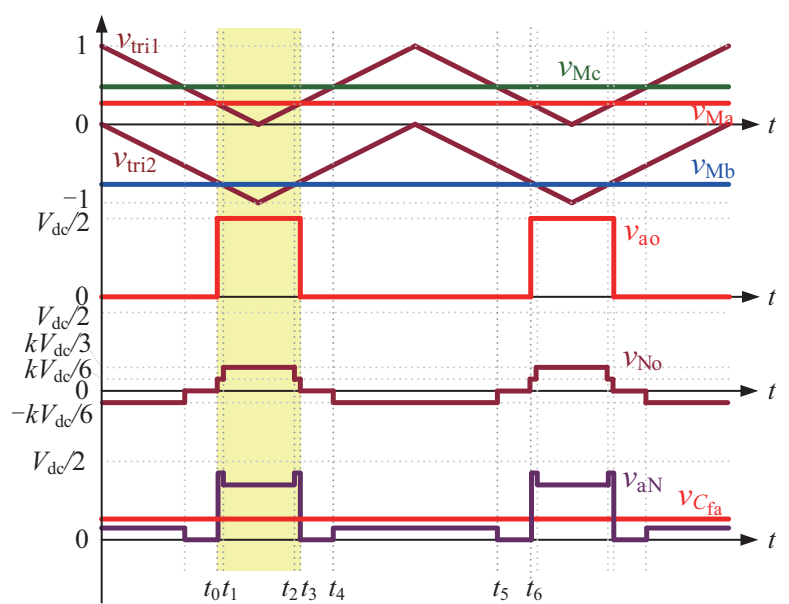

(a)

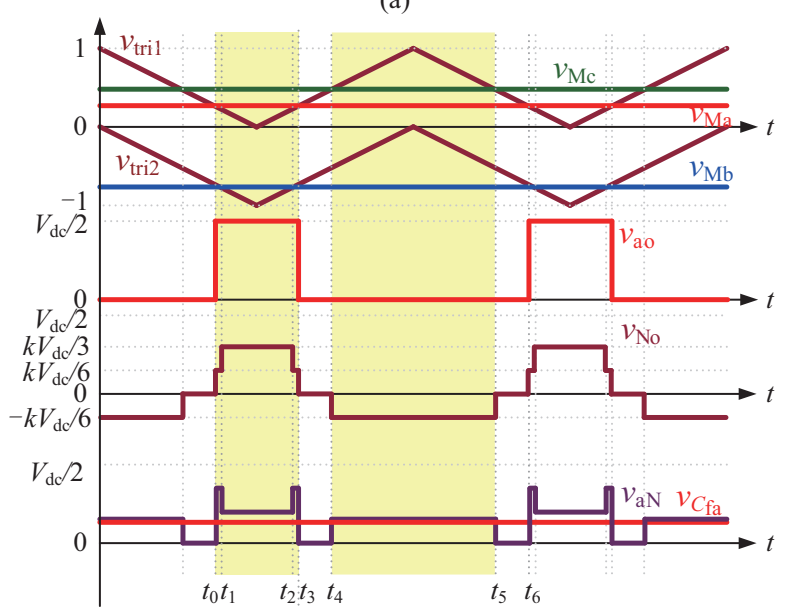

(b)

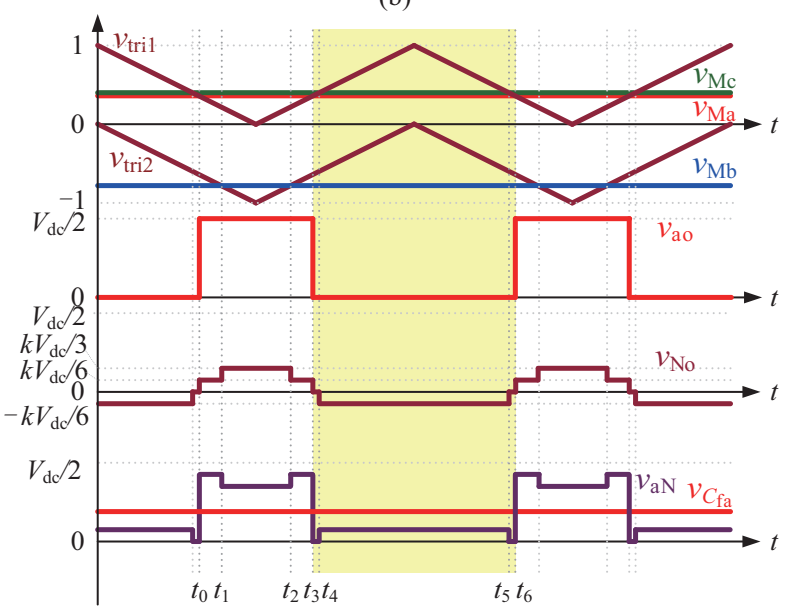

(c)

Fig. 7. Key waveforms of phase $a$ for $\omega t \in\left[\alpha_{1}, \pi / 6\right]$. (a) $\omega t \in\left[\alpha_{1}, \beta\right]$ and $0 \leq k$ $\leq 3 M \sin \omega t$ (b) $\omega t \in\left[\alpha_{1}, \beta\right]$ and $3 M \sin \omega t<k \leq 1$. (c) $\omega t \in[\beta, \pi / 6]$.

$L_{\mathrm{f} 23}=\frac{1}{\Delta I_{L}}\left[v_{\mathrm{Ma}} \frac{V_{\mathrm{dc}}}{2}\left(v_{\mathrm{Mc}}-v_{\mathrm{Ma}}\right)+\left(v_{\mathrm{Ma}}-\frac{1}{3} k\right) \frac{V_{\mathrm{dc}}}{2}\left(1-v_{\mathrm{Mc}}\right)\right] T_{\mathrm{s}}$

Case 3: $\omega t \in\left(\pi / 6, \alpha_{3}\right)$

In this case, $v_{\mathrm{Ma}}$ is the first one intersecting with the carrier waveform, $v_{\mathrm{Mc}}$ the second, and $v_{\mathrm{Mb}}$ the third, as shown in Fig.

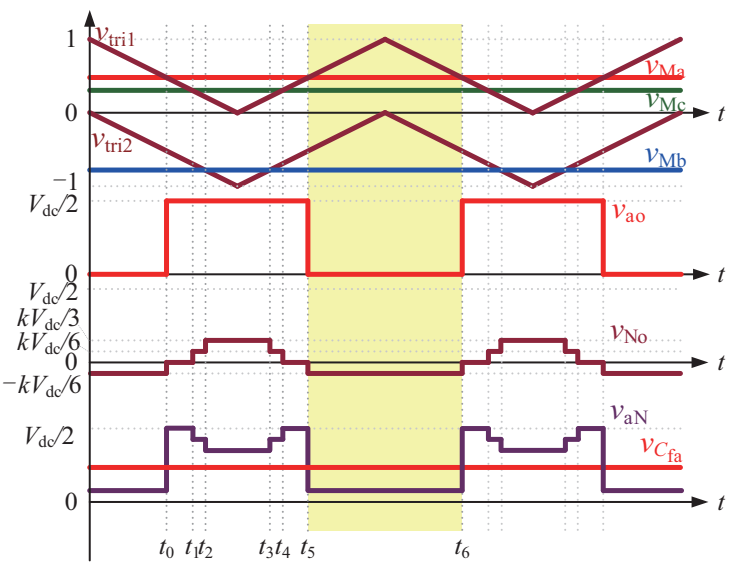

Fig. 8. Key waveforms of phase $a$ for $\omega t \in\left[\pi / 6, \alpha_{3}\right]$.

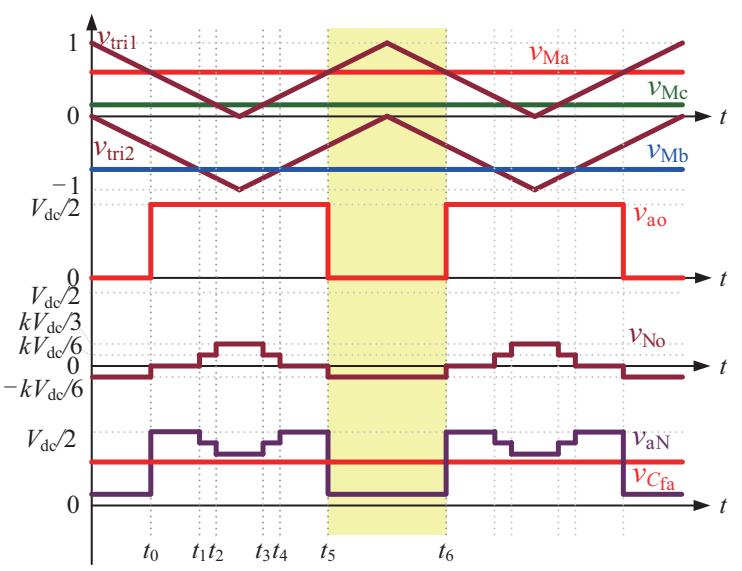

Fig. 9. Key waveforms of phase a for $\omega t \in\left[\alpha_{3}, \pi / 3\right]$.

8. $v_{\mathrm{No}}$ has four voltage levels, i.e., $k V_{\mathrm{dc}} / 3, k V_{\mathrm{dc}} / 6,0$, and $-k V_{\mathrm{dc}} / 6$. Accordingly, $v_{\mathrm{aN}}$ has four voltage levels, i.e., $(1 / 2-k / 3) V_{\mathrm{dc}},(1 / 2$ $-k / 6) V_{\mathrm{dc}}, 1 / 2 V_{\mathrm{dc}}$, and $k V_{\mathrm{dc}} / 6$.

For $\omega t \in\left(\pi / 6, \alpha_{3}\right), v_{C \mathrm{fa}}\left(=V_{\mathrm{dc}} v_{\mathrm{Ma}} / 2\right)>V_{\mathrm{dc}} / 6 \geq k V_{\mathrm{dc}} / 6$. Thus, $i_{L_{\mathrm{a}}}$ always decreases from $t_{5}$ till $t_{6}$ whichever of $v_{C_{\mathrm{fa}}}$ or $(1 / 2-$ $k / 3) V_{\mathrm{dc}}$ is higher, as highlighted in Fig. 8. Thus, the minimum required inductance will be

$$
L_{\mathrm{f} 3}=\frac{1}{\Delta I_{L}}\left(v_{\mathrm{Ma}}-\frac{1}{3} k\right) \frac{V_{\mathrm{dc}}}{2}\left(1-v_{\mathrm{Ma}}\right) T_{\mathrm{s}}
$$

Case 4: $\omega t \in\left(\alpha_{3}, \pi / 3\right)$

In this case, $v_{\mathrm{Ma}}$ is the first one intersecting with the carrier waveform, $v_{\mathrm{Mb}}$ the second, and $v_{\mathrm{Mc}}$ the third, as shown in Fig. 9. $v_{\mathrm{No}}$ has four voltage levels, i.e., $k V_{\mathrm{dc}} / 3, k V_{\mathrm{dc}} / 6,0$, and $-k V_{\mathrm{dc}} / 6$. Accordingly, $v_{\mathrm{aN}}$ has four voltage levels, i.e., $(1 / 2-k / 3) V_{\mathrm{dc}},(1 / 2$ $-k / 6) V_{\mathrm{dc}}, 1 / 2 V_{\mathrm{dc}}$, and $k V_{\mathrm{dc}} / 6$.

Similar with Case $3, v_{\mathrm{Cfa}}\left(=V_{\mathrm{dc}} v_{\mathrm{Ma}} / 2\right)>V_{\mathrm{dc}} / 6 \geq k V_{\mathrm{dc}} / 6$, such that $i_{L_{\mathrm{a}}}$ always decreases within $\left[t_{5}, t_{6}\right]$ regardless of the values of $v_{\mathrm{Cfa}_{\mathrm{f}}}$ and $(1 / 2-k / 3) V_{\mathrm{dc}}$, as highlighted in Fig. 9. So, the minimum required inductance for this case will be also

$$
L_{\mathrm{f} 4}=\frac{1}{\Delta I_{L}}\left(v_{\mathrm{Ma}}-\frac{1}{3} k\right) \frac{V_{\mathrm{dc}}}{2}\left(1-v_{\mathrm{Ma}}\right) T_{\mathrm{s}}
$$




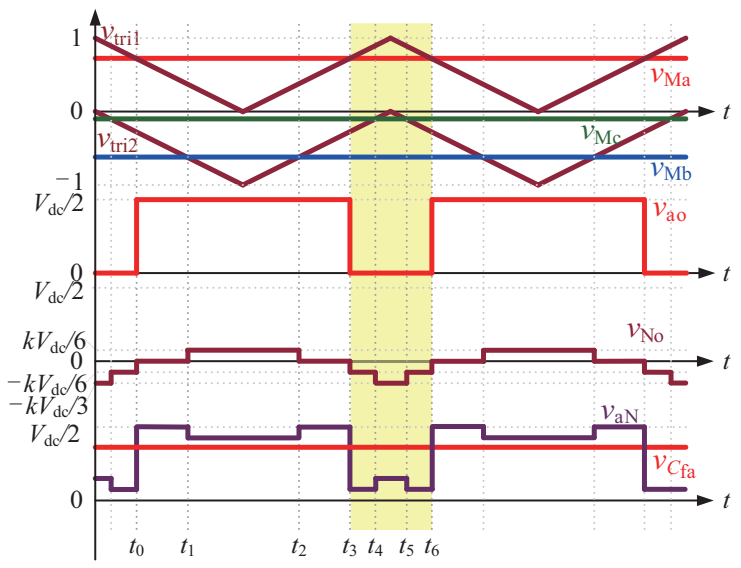

Fig. 10. Key waveforms of phase $a$ for $\omega t \in\left[\pi / 3, \alpha_{4}\right]$.

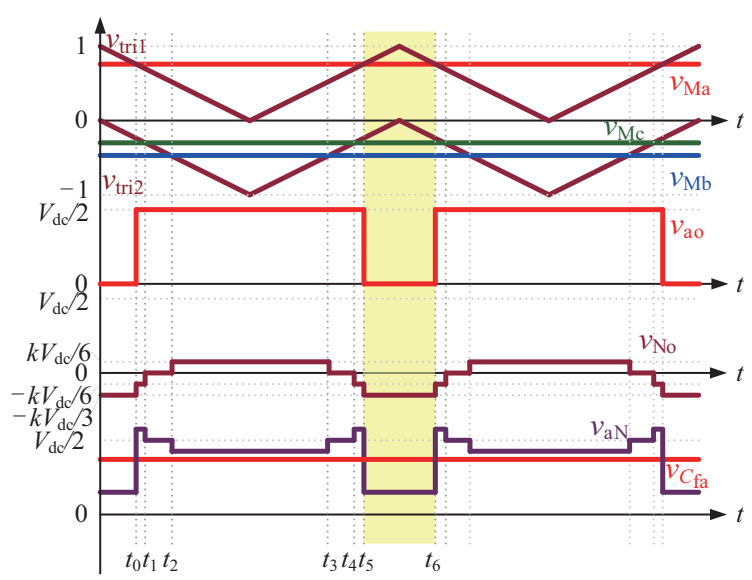

Fig. 11. Key waveforms of phase $a$ for $\omega t \in\left[\alpha_{4}, \pi / 2\right]$.

Case 5: $\omega t \in\left(\pi / 3, \alpha_{4}\right)$

In this case, $v_{\mathrm{Mc}}$ is the first one intersecting with the carrier waveform, $v_{\mathrm{Ma}}$ the second, and $v_{\mathrm{Mb}}$ the third, as shown in Fig. 10. $v_{\mathrm{No}}$ has four voltage levels, i.e., $k V_{\mathrm{dc}} / 6,0,-k V_{\mathrm{dc}} / 6$, and $k V_{\mathrm{dc}} / 3$. Accordingly, $v_{\mathrm{aN}}$ has four voltage levels, i.e., $(1 / 2-k / 6)$ $V_{\mathrm{dc}}, 1 / 2 V_{\mathrm{dc}}, k V_{\mathrm{dc}} / 6$ and $k V_{\mathrm{dc}} / 3$.

For $\omega t \in\left(\pi / 3, \alpha_{4}\right)$, we have $v_{\mathrm{Cfa}}\left(=V_{\mathrm{dc}} v_{\mathrm{Ma}} / 2\right) \geq \sqrt{3} v_{\mathrm{dc}} / 3$ $>k V_{\mathrm{dc}} / 3 \geq k V_{\mathrm{dc}} / 6$. Thus, $i_{L_{\mathrm{a}}}$ always decreases within $\left[t_{3}, t_{6}\right]$, as highlighted in Fig. 10. Thus, the minimum required inductance will be

$$
\begin{gathered}
L_{\mathrm{f} 5}=\frac{1}{\Delta I_{L}}\left(v_{\mathrm{Ma}}-\frac{1}{3} k\right) \frac{V_{\mathrm{dc}}}{2}\left(v_{\mathrm{Mc}}+1-v_{\mathrm{Ma}}\right) T_{\mathrm{s}} \\
+\frac{1}{\Delta I_{L}}\left(v_{\mathrm{Ma}}-\frac{2}{3} k\right) \frac{V_{\mathrm{dc}}}{2}\left(-v_{\mathrm{Mc}}\right) T_{\mathrm{s}}
\end{gathered}
$$

Case 6: $\omega t \in\left(\alpha_{4}, \pi / 2\right)$

In this case, $v_{\mathrm{Ma}}$ is the first one intersecting with the carrier waveform, $v_{\mathrm{Mc}}$ the second, and $v_{\mathrm{Mb}}$ the third, as shown in Fig. 11. $v_{\mathrm{No}}$ has four voltage levels, i.e., $k V_{\mathrm{dc}} / 6,0,-k V_{\mathrm{dc}} / 6$, and $k V_{\mathrm{dc}} / 3$. Accordingly, $v_{\mathrm{aN}}$ has four voltage levels, i.e., $(1 / 2-k / 6)$ $V_{\mathrm{dc}}, 1 / 2 V_{\mathrm{dc}}, 1 / 2 V_{\mathrm{dc}}+k V_{\mathrm{dc}} / 6$ and $k V_{\mathrm{dc}} / 3$.

Like Case $5, i_{L_{\mathrm{a}}}$ always decreases within $\left[t_{5}, t_{6}\right]$. Thus, the minimum required inductance will be

$$
L_{\mathrm{f} 6}=\frac{1}{\Delta I_{L}}\left(v_{\mathrm{Ma}}-\frac{2}{3} k\right) \frac{V_{\mathrm{dc}}}{2}\left(1-v_{\mathrm{Ma}}\right) T_{\mathrm{s}}
$$

Summarizing from the above-mentioned discussions, $L_{\mathrm{fa}}$ can be written as

$$
L_{\mathrm{fa}}= \begin{cases}L_{\mathrm{f} 11} & \omega t \in\left(0, \alpha_{1}\right) \cap k \in[0,3 M \sin \omega t) \\ L_{\mathrm{f} 12} & \omega t \in\left(0, \alpha_{1}\right) \cap k \in[3 M \sin \omega t, 1] \\ L_{\mathrm{f} 21} & \omega t \in\left[\alpha_{1}, \beta\right) \cap k \in[0,3 M \sin \omega t) \\ L_{\mathrm{f} 22} & \omega t \in\left[\alpha_{1}, \beta\right) \cap k \in[3 M \sin \omega t, 1] \\ L_{\mathrm{f} 23} & \omega t \in[\beta, \pi / 6) \\ L_{\mathrm{f} 3} & \omega t \in\left[\pi / 6, \alpha_{3}\right) \\ L_{\mathrm{f} 4} & \omega t \in\left[\alpha_{3}, \pi / 3\right) \\ L_{\mathrm{f} 5} & \omega t \in\left[\pi / 3, \alpha_{4}\right) \\ L_{\mathrm{f} 6} & \omega t \in\left[\alpha_{4}, \pi / 2\right)\end{cases}
$$

$L_{\text {fmin }}$ for phase $a$ will be determined by the maximum value of $L_{\mathrm{fa}}$ over all cases. Thus, $L_{\mathrm{fmin}}$ will be

$$
L_{\mathrm{fmin}}=\max \left\{L_{\mathrm{f} a}\right\}
$$

Recalling (3) in which $k$ is defined as $3 L_{N} /\left(L_{\mathrm{f}}+3 L_{N}\right)$, we have

$$
L_{N}=\frac{k}{1-k} \frac{1}{3} L_{\text {fmin }}
$$

So, the total required ac filter inductance will be

$$
L_{\mathrm{sum}}=L_{N}+\sum_{x=a, b, c} L_{\mathrm{f} x}=\left(\frac{1}{3} \frac{k}{1-k}+3\right) L_{\mathrm{fmin}}
$$

Obviously, $L_{\text {fmin }}, L_{N}$, and $L_{\text {sum }}$ are all functions of $k$.

Please note that the inductor current and neutral current will induce voltage drop across $L_{\mathrm{fa}}$ and $L_{N}$ which might result in overmodulation if either $L_{\mathrm{fa}}$ or $L_{N}$ is too large. To avoid this problem, $L_{\mathrm{fa}}$ and $L_{N}$ should also satisfy

$$
\left|\dot{V}_{C_{\mathrm{f} a}}+\mathrm{j} \omega L_{\mathrm{f} a} \dot{I}_{L_{a}}+\mathrm{j} \omega L_{N} \dot{I}_{N}\right|<V_{\mathrm{in}} / 2
$$

In general, the filter capacitor in each phase is designed to keep the capacitor current within $5 \%$ of the rated phase current. So, $I_{L_{\mathrm{a}}} \approx I_{\mathrm{a}}$. Considering the worst case for (20), we have

$$
\begin{aligned}
& \left|\dot{V}_{C_{\mathrm{fa} a}}+\mathrm{j} \omega L_{\mathrm{fa}} \dot{I}_{L_{a}}+\mathrm{j} \omega L_{N} \dot{I}_{N}\right|<\left|\dot{V}_{C_{\mathrm{fa} a}}\right|+\left|j \omega L_{\mathrm{fa}} \dot{I}_{L_{a}}\right|+\left|j \omega L_{N} \dot{I}_{N}\right| \\
& =M V_{\mathrm{dc}} / 2+\sqrt{2} \omega L_{\mathrm{fa}} I_{\mathrm{a}}+\sqrt{2} \omega L_{N} \lambda I_{a}<V_{\mathrm{dc}} / 2
\end{aligned}
$$

in which $\lambda \in[0,1]$ is the load unbalanced factor. If the threephase loads are well balanced, $\lambda$ is 0 . On the contrary, if two phases are with full load whereas the third one is with no load, 
TABLE II

SPECIFICATIONS For THREE-PHASE T-TYPe INVERTER

\begin{tabular}{lcc}
\hline \hline Parameter & Symbol & Value \\
\hline DC Input Voltage & $V_{\mathrm{dc}}$ & $800 \mathrm{~V}$ \\
AC Phase Voltage & $V_{C_{\mathrm{fa}}}, V_{C_{\mathrm{fb}}}, V_{C_{\mathrm{fc}}}$ & $220 \mathrm{~V}(\mathrm{RMS})$ \\
Phase Current & $I_{\mathrm{a}}, I_{\mathrm{b}}, I_{\mathrm{c}}$ & $15.2 \mathrm{~A}(\mathrm{RMS})$ \\
Output Frequency & $f_{\mathrm{o}}$ & $50 \mathrm{~Hz}$ \\
Apparent Power & $S$ & $10 \mathrm{kVA}$ \\
\hline \hline
\end{tabular}

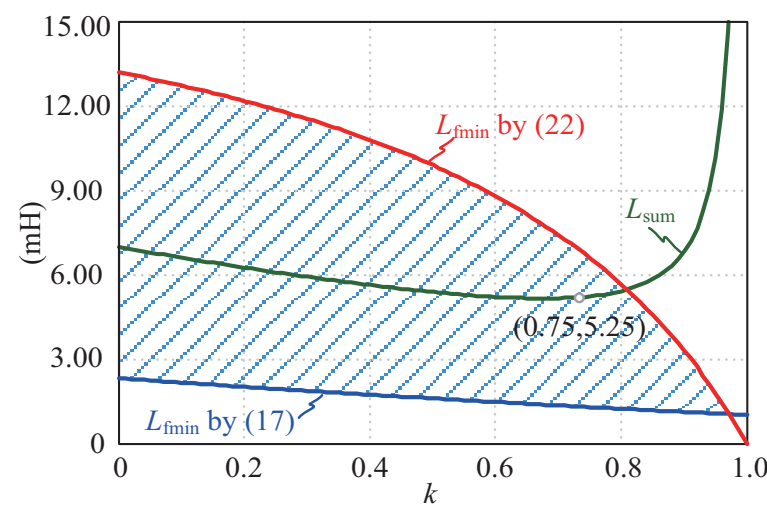

Fig. 12. Plots of $L_{\text {finin }}$ and $L_{\text {sum }}$ against $k$.

$\lambda$ is 1 .

By submitting (17) and (18) into (20), yields

$$
L_{\mathrm{fmin}}<\frac{1}{\sqrt{2} \omega I_{a}} \frac{1}{1+\lambda k /[3(1-k)]}(1-M) \frac{V_{\mathrm{dc}}}{2}
$$

Using the parameters given in Table II (referring to Section V), Fig. 12 illustrates the plots of (17) and (22). Based on (19), the plot of $L_{\text {sum }}$ is also depicted. Within the shaded area (possible area for $L_{\text {fmin }}$ and $k$ ), the minimum required total filter inductance, $L_{\text {sum min }}$, is $5.25 \mathrm{mH}$ when $k=0.75$.

In light of (16), Fig. 13 shows the plots of $L_{\mathrm{fa}}$ with $k=0, k=$ 0.75 , and $k=1$. As seen, the total required filter inductance for the basic 3P4W T-type inverter $(k=0)$ is $7.05 \mathrm{mH}(2.35 \mathrm{mH}$ per phase), which is more than twice the total required filter inductance (1.04 $\mathrm{mH}$ per phase) for the 3P3W T-type inverter ( $k$ $=1$ ). Thanks to the insertion of $L_{N}(1.35 \mathrm{mH})$, the total required filter inductance $(5.25 \mathrm{mH})$ can be saved by $25 \%$ compared to the total required filter inductance for the basic 3P4W T-type inverter. Please keep in mind that lower load unbalanced factor results in lower current rating for $L_{N}$. This means the size and volume of $L_{N}$ will be much lower than that of $L_{\mathrm{fx}}$ with similar inductance. Therefore, the insertion of $L_{N}$ will benefit more for filter size and volume reduction in the application where the $3 \mathrm{P} 4 \mathrm{~W}$ inverter supplies the unbalanced three phase load with low unbalanced factor.

\section{Zero-Sequence Voltage Control for 3P4W T-TYPE INVERTER}

Because of the existence of neutral wire, the 3P4W inverter

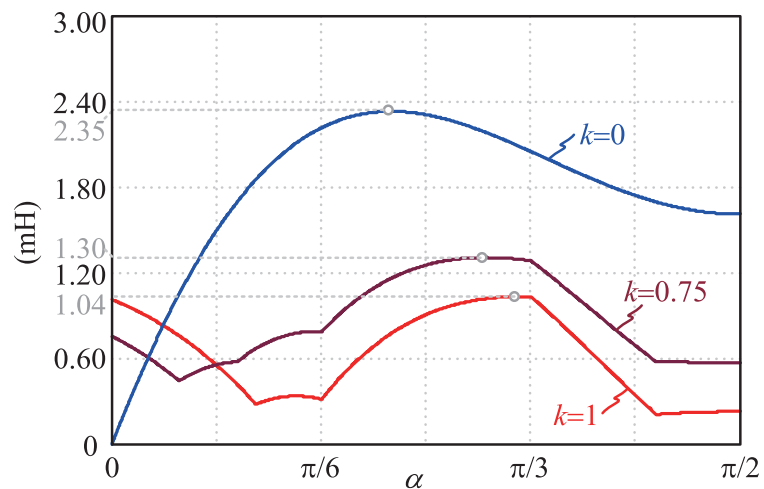

Fig. 13. Shows the plots of $L_{\mathrm{fa}}$ with $k=0, k=0.75$, and $k=1$.

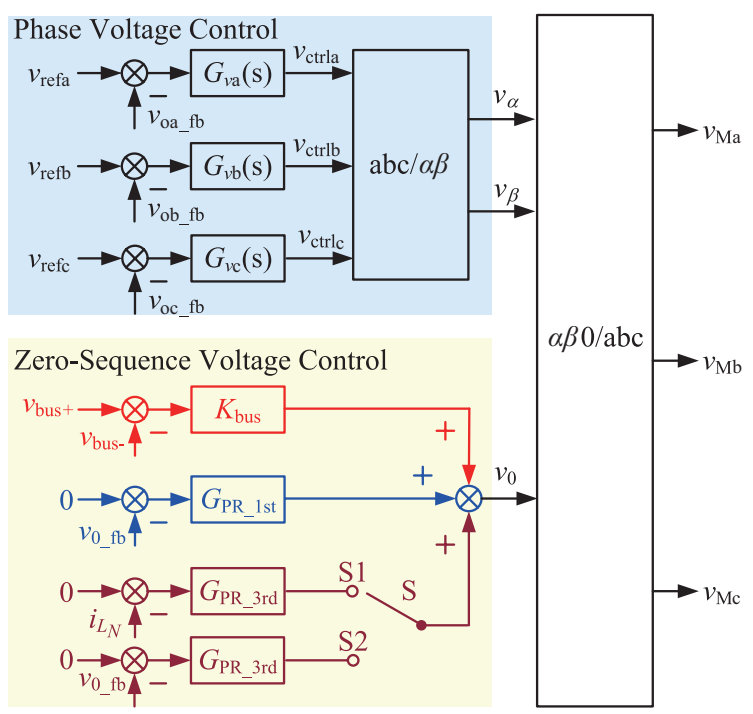

Fig. 14. Control block diagram of 3P4W T-type inverter.

can be deemed as three decoupled single-phase inverters with phase voltages interleaved by $120^{\circ}$ [17]. As a result, each phase voltage can be independently regulated in the abc-frame, as shown in Fig. 14. In addition to the phase voltage regulation, the upper and lower dc bus voltages, i.e., $v_{\text {bus }}$ and $v_{\text {bus }}$ in Fig. 3, should be balanced [18]-[20]. To attain this objective, we can compare $v_{\text {bust }}$ with $v_{\text {bus }}$ and use the error voltage to regulate the zero-sequence component of the modulation waveforms, as we usually do for the 3P3W T-type inverter.

Different from the 3P3W T-type inverter, however, the neutral wire in the 3P4W T-type inverter provides the path for zero-sequence currents which might make load voltages unbalanced or distorted. To mitigate the potential problems, this section shows the dedicated zero-sequence voltage control for the 3P4W T-type inverter.

\section{A. Zero-Sequence Fundamental Voltage Elimination for Balancing Load Voltages}

When supplying unbalanced loads, fundamental zerosequence current will flow through the neutral wire. Since the 


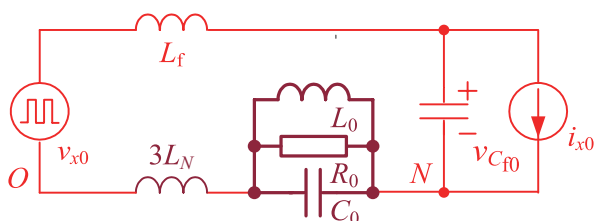

Fig. 15. Insertion of $R L C$ network in the neutral wire.

neutral current flows into the midpoint of the split capacitor leg, there will be fundamental voltage ripples in $v_{\text {bust }}$ and $v_{\text {bus- }}$ Therefore,the error of $v_{\text {bust }}$ and $v_{\text {bus- }}$ will have fundamental voltage ripples, leading to fundamental zero-sequence voltage in modulation waveforms. This way, the load voltages will have fundamental zero-sequence component and become unbalanced.

In order to have balanced load voltages, the zero-sequence fundamental voltage should be eliminated from the modulation waveforms. Aiming for this, a resonant controller, written by

$$
G_{\mathrm{PR}_{-} 1 \mathrm{st}}(s)=\frac{K_{r 1 \mathrm{st}} \omega_{\mathrm{i}} s}{s^{2}+\omega_{\mathrm{i}} s+\left(2 \pi f_{\mathrm{o}}\right)^{2}}
$$

whose resonant frequency is mapped at the fundamental output frequency $f_{\mathrm{o}}$ is inserted into the zero-sequence voltage loop, as highlighted in blue in Fig. 14. This way, the zero-sequence fundamental component will be eliminated from the load voltages because of the particularly high zero-sequence voltage loop gain at $f_{0}$, making the load voltages well balanced even if the loads have the highest unbalanced factor $(\lambda=1)$.

\section{B. Third-Order Harmonic Current Elimination for Reducing Load Voltage Distortion}

Unlike the $2 \mathrm{~L}$ voltage-source converter, the midpoint current of the T-type inverter, i.e., $i_{\text {mid }}$ inherently pulsates at $3 f_{\text {o }}$ with LS-SPWM, inducing third-order harmonic ripples in $v_{\text {bust }}$ and $v_{\text {bus }}$ [16] which will in turn produce third-order harmonic voltage in the output of each phase-leg $\left(v_{x o}\right)$.

As illustrated in Fig. 4, the third-order harmonic voltage in $v_{x o}$ will finally forms third-order harmonic current circulating along the L-C filters and the neutral wire. Consequently, the three-phase load voltage will be polluted, leading to voltage distortion and thereby higher THD.

To block the third-order harmonic current, we can insert a paralleled $R L C$ network, with $L_{0}$ being parallel-resonant with $C_{0}$ at $3 f_{0}$, in the neutral wire, as shown in Fig. 15. The impedance of the $R L C$ network is

$Z_{R L C}(s)=\frac{1}{1 / R_{0}+1 / s L_{0}+s C_{0}}=\frac{\left(L_{0} / C_{0}\right) s}{s^{2}+\left[1 /\left(R_{0} C_{0}\right)\right] s+\left(2 \pi 3 f_{0}\right)^{2}}$

whose format is the same as a resonant controller, written by

$$
G_{\mathrm{PR}_{-} 3 \mathrm{rd}}(s)=\frac{K_{\mathrm{r} 3 \mathrm{rd}} \omega_{\mathrm{i}} s}{s^{2}+\omega_{\mathrm{i}} s+\left(2 \pi 3 f_{\mathrm{o}}\right)^{2}}
$$

TABLE III

Parameters of L-C Filters in Different Configurations

\begin{tabular}{lccc}
\hline \hline Configuration & $L_{\mathrm{f}}(\mathrm{mH})$ & $L_{N}(\mathrm{mH})$ & $C_{\mathrm{f}}(\mu \mathrm{F})$ \\
\hline 3P3W & 1.04 & $/$ & 10 \\
3P4W w/o $L_{N}$ & 2.35 & $/$ & 10 \\
3P4W w/ $L_{N}$ & 1.30 & 1.35 & 10 \\
\hline \hline
\end{tabular}

with the resonant frequency mapped at $3 f_{\mathrm{o}}$ [22]-[25]. This indicates that the paralleled $R L C$ network can be emulated by inserting a resonant controller in the neutral current control loop, as shown in Fig. 14 with S closed to S1.

As for the three-phase load voltages, the third-order harmonic voltage is also a type of zero-sequence voltage. As an alternative, therefore, we could also eliminate the third-order harmonic voltage by increasing the zero-sequence voltage loop gain at $3 f_{\mathrm{o}}$. With this consideration, the other resonant controller, with the resonant frequency at $3 f_{\mathrm{o}}$ can be further introduced into the zero-sequence voltage loop, as shown in Fig. 14 with S closed to S2. In this manner, not only the fundamental zero-sequence voltage but also the third-order zero-sequence voltage will be eliminated from the three-phase load voltages, resulting in balanced and sinusoidal three-phase voltage for both balanced and unbalanced loads.

\section{EXPERIMENTAL RESULTS}

In the lab, a 10-kVA three-phase T-type inverter has been fabricated and tested to validate the proposed work. Table II and III respectively give the prototype specifications and the filter parameters for different configurations.

Figs. 16(a) and (b) show the load voltages and inductor currents for the T-type inverter under balanced full loads in $3 \mathrm{P} 3 \mathrm{~W}$ and $3 \mathrm{P} 4 \mathrm{~W}$ configuration, respectively, with $L_{\mathrm{f}}=1.04$ $\mathrm{mH}$. Despite the same filter inductance, the inductor current ripple in $3 \mathrm{P} 4 \mathrm{~W}$ configuration is apparently higher than that in $3 \mathrm{P} 3 \mathrm{~W}$ configuration. By increasing the filter inductor from $1.04 \mathrm{mH}$ to $2.35 \mathrm{mH}$, the inductor current ripple in $3 \mathrm{P} 4 \mathrm{~W}$ configuration, as shown in Fig. 16(c), is reduced to the same level $\left(20 \% I_{x}\right)$ as the inductor current ripple given in Fig. 16(a). This confirms the theoretical analyses in Section III. After inserting the neutral inductor $(1.35 \mathrm{mH})$, the inductor current ripple given in Fig. 16(d) is the same as that shown in Fig. 16 (c), but $L_{\mathrm{f}}$ is reduced from $2.35 \mathrm{mH}$ to $1.30 \mathrm{mH}$. This demonstrates that the inserted neutral inductor can help save the total filter inductance in the 3P4W $3 \mathrm{~L}$ inverter.

Fig. 17 gives the load voltages and inductor currents for the 3P4W T-type inverter under unbalanced loads (full-load in phase $a$ and $b$, whereas $2 / 3$ full-load in phase $c$ ). Similar to the results for balanced loads, the inductor current ripple with $L_{\mathrm{f}}=$ $1.04 \mathrm{mH}$, as shown in Fig. 17(a), is much higher than that with $L_{\mathrm{f}}=2.35 \mathrm{mH}$, as shown in Fig. 17(b). By inserting the neutral inductor $(1.35 \mathrm{mH})$, the inductor current ripple, as shown in Fig. 17(c), becomes the same as that shown in Fig. 17(b), with $L_{\mathrm{f}}$ reduced to $1.30 \mathrm{mH}$.

Fig. 18 shows the load voltages and currents for the 3P4W 


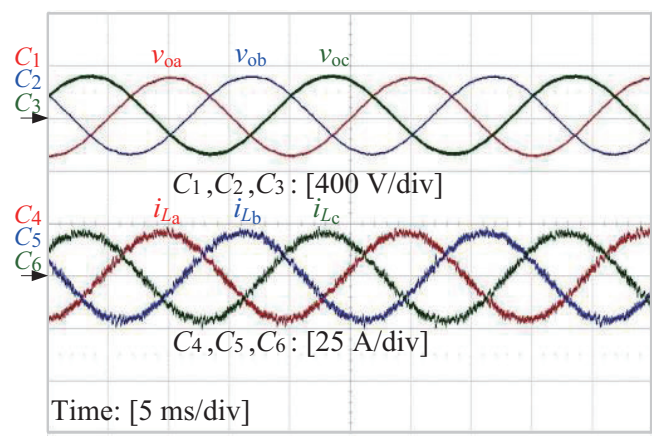

(a)

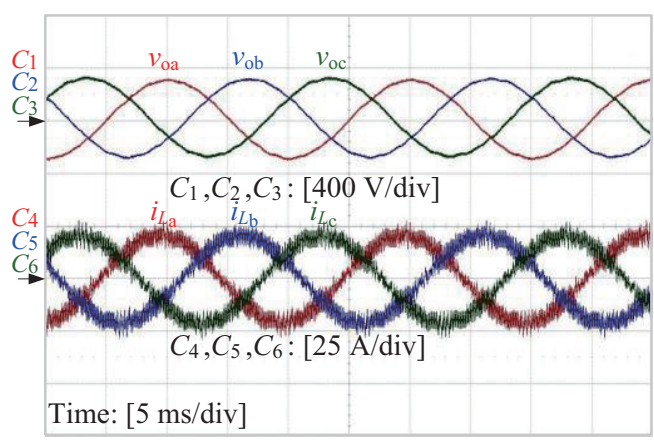

(b)

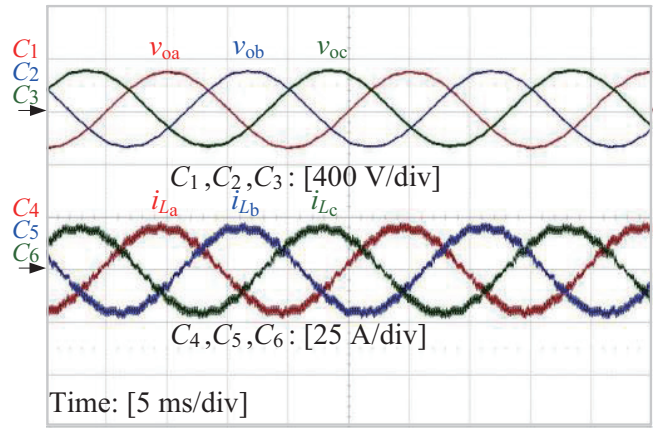

(c)

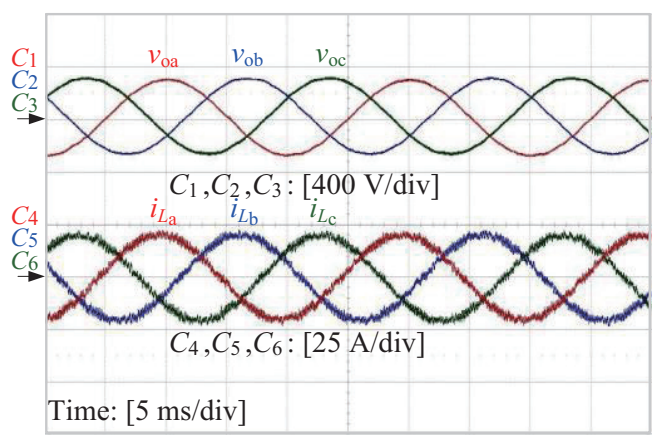

(d)

Fig. 16. Load voltages and inductor currents under balanced full loads. (a) 3P3W with $L_{\mathrm{f}}=1.04 \mathrm{mH}$. (b) $3 \mathrm{P} 4 \mathrm{~W}$ with $L_{\mathrm{f}}=1.04 \mathrm{mH}$. (c) $3 \mathrm{P} 4 \mathrm{~W}$ with $L_{\mathrm{f}}=2.35$ mH. (d) 3P4W with $L_{\mathrm{f}}=1.30 \mathrm{mH}$ and $L_{\mathrm{N}}=1.35 \mathrm{mH}$.

T-type inverter under full balanced loads, where Fig. 18(a) is for the inverter without $G_{\mathrm{PR} 1 \mathrm{st}}(s)$ or $G_{\mathrm{PR} 3 \mathrm{rd}}(s)$; Fig. 18(b) for the inverter with $G_{\mathrm{PR} \_1 s t}(s)$ but without $G_{\mathrm{PR}_{-} 3 \mathrm{rd}}(s)$; Fig. $18(\mathrm{c})$ for

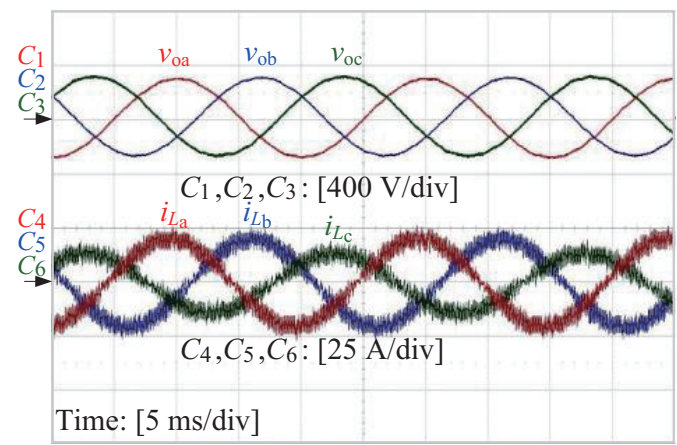

(a)

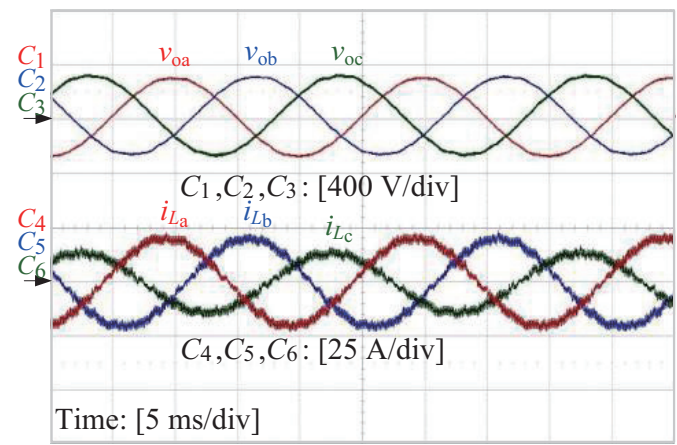

(b)

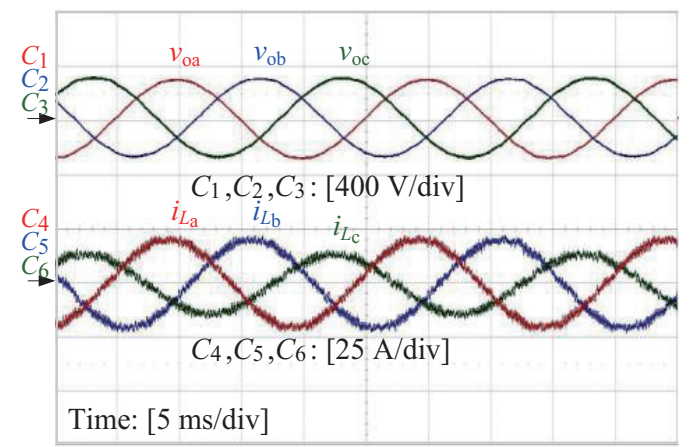

(c)

Fig. 17. Load voltages and inductor currents under unbalanced loads. (a) $3 \mathrm{P} 4 \mathrm{~W}$ with $L_{\mathrm{f}}=1.04 \mathrm{mH}$. (b) $3 \mathrm{P} 4 \mathrm{~W}$ with $L_{\mathrm{f}}=2.35 \mathrm{mH}$. (c) $3 \mathrm{P} 4 \mathrm{~W}$ with $L_{\mathrm{f}}=1.30$ $\mathrm{mH}$ and $L_{N}=1.35 \mathrm{mH}$.

the inverter with $G_{\mathrm{PR} \_ \text {st }}(s)$ and $G_{\mathrm{PR} \_ \text {rd }}(s)$ in the zero-sequence voltage loop; and Fig. 18(d) for the inverter with $G_{\mathrm{PR} 1 \mathrm{st}}(s)$ in zero-sequence voltage loop plus $G_{\mathrm{PR} 3 \mathrm{rd}}(s)$ in the neutral current loop. The load-voltage unbalanced factor (UBF) and loadvoltage THD are summarized in Table IV. Because of balanced loads, the load voltages in Fig. 18 are all balanced. In contrast with Figs. 18(c) and (d), however, the load voltages in Figs. 18(a) and (b) are distorted because of the third-order harmonic, making the THD increased to $6.0 \%$, indicating that $G_{\mathrm{PR} 3 \mathrm{rd}}(s)$ in the zero-sequence voltage (or current) loop is effective for preventing the load voltages from being distorted.

Keeping the same control parameters, Fig. 19 shows the test results for unbalanced loads (full-load in phase $a$ and $b$, whereas no-load in phase $c$ ). Without adding $G_{\mathrm{PR} 1 \mathrm{st}}(s)$ or $G_{\mathrm{PR} 3 \mathrm{rd}}(s)$, the load voltages are unbalanced and distorted, as 


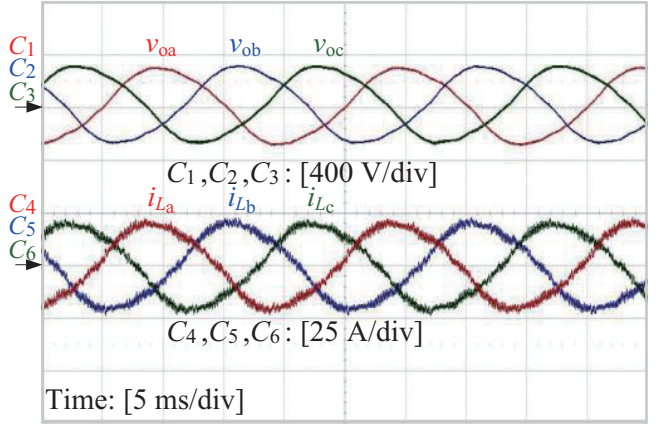

(a)

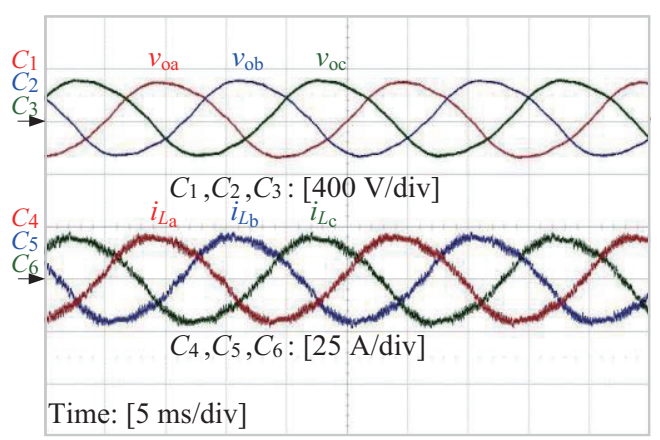

(b)

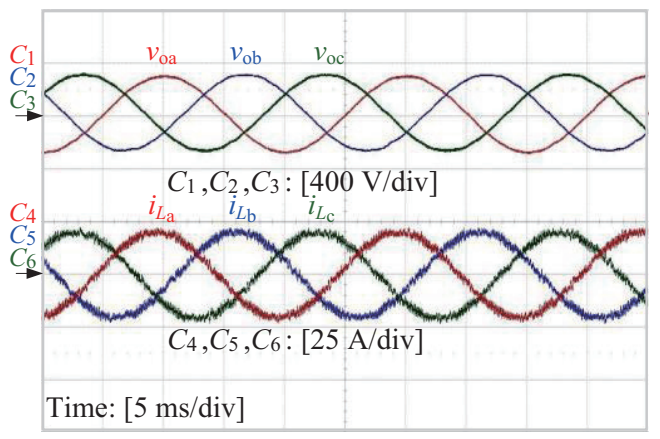

(c)

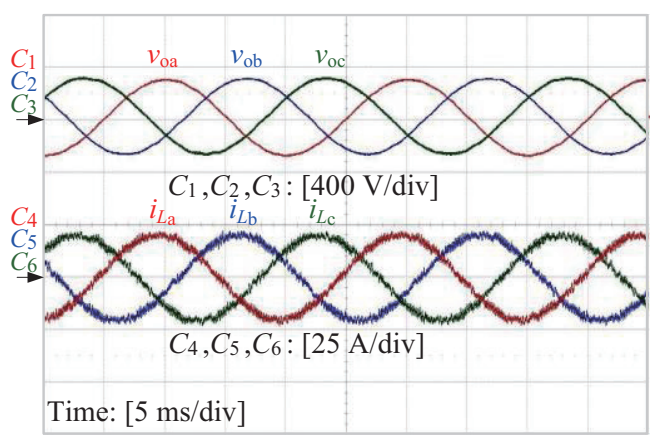

(d)

Fig. 18. Load voltages and inductor currents for 3P4W T-type inverter under balanced full loads. (a) Without $G_{\mathrm{PR}_{1} \text { st }}(s)$ or $G_{\mathrm{PR}_{3} \text { rdd }}(s)$. (b) With $G_{\mathrm{PR}_{1} \text { st }}(s)$ but without $G_{\mathrm{PR}_{3} \text { rd }}(s)$. (c) With $G_{\mathrm{PR}_{1} \text { st }}(s)$ and $G_{\mathrm{PR}_{-} 3 \mathrm{rd}}(s)$ in zero-sequence voltage loop. (d) With $G_{\mathrm{PR} \_ \text {1st }}(s)$ in zero-sequence voltage loop and $G_{\mathrm{PR} \_ \text {3rd }}(s)$ in neutral current loop.

shown in Fig. 19(a). By merely inserting $G_{\mathrm{PR} 1 \mathrm{st}}(s)$ in the zerosequence voltage loop, the load voltages become balanced, but still have distortion, as shown in Fig. 19(b). With the further

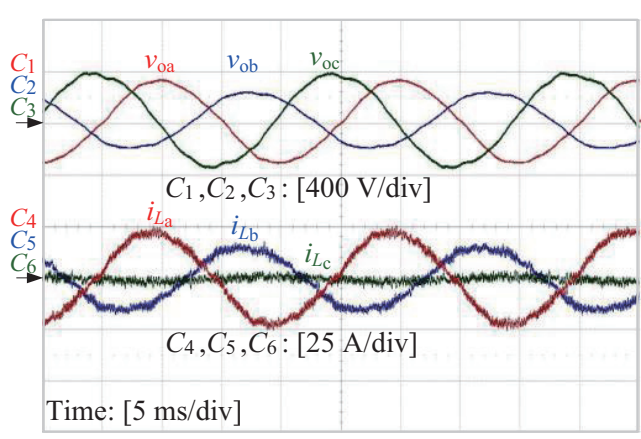

(a)

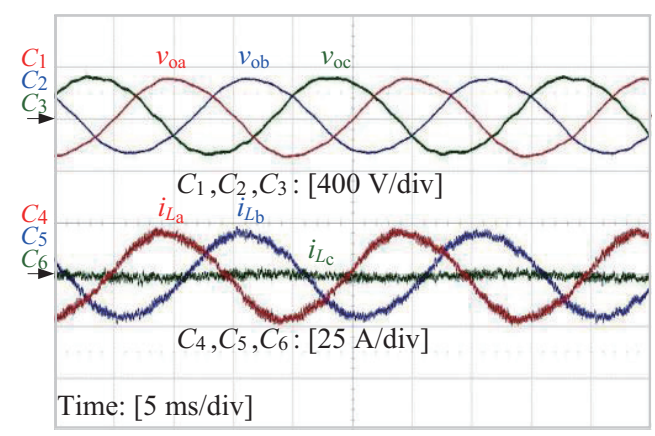

(b)

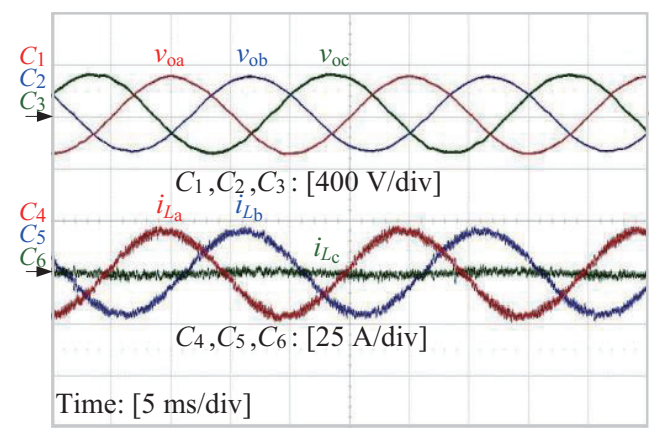

(c)

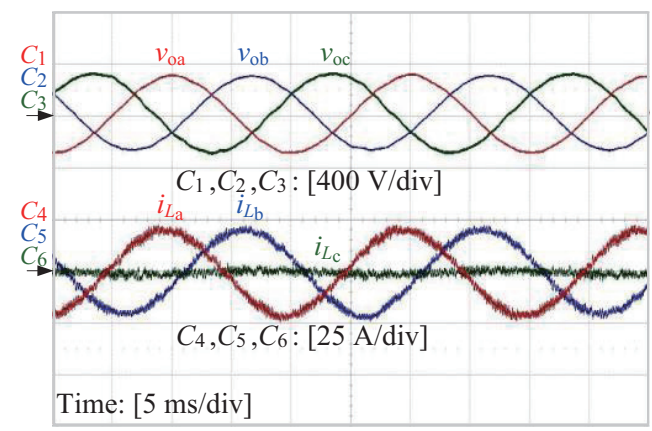

(d)

Fig. 19. Load voltages and inductor currents for 3P4W T-type inverter under unbalanced loads. (a) Without $G_{\mathrm{PR}_{\_} 1 \mathrm{st}}(s)$ or $G_{\mathrm{PR} \_3 \mathrm{rd}}(s)$. (b) With $G_{\mathrm{PR} \_1 \mathrm{st}}(s)$ in the zero-sequence voltage loop but without $G_{\mathrm{PR}_{-} 3 \mathrm{rd}}(s)$. (c) With $G_{\mathrm{PR} \_1 s t}(s)$ and $G_{\mathrm{PR} \_3 r d}(s)$ in the zero-sequence voltage loop. (d) With $G_{\mathrm{PR}_{-} 1 \text { st }}(s)$ in the zerosequence voltage loop and $G_{\mathrm{PR} 3 \mathrm{rd}}(s)$ in the neutral current loop.

addition of $G_{\mathrm{PR} 3 \mathrm{rd}}(s)$ in the zero-sequence voltage (or neutral current) loop, the load voltages are not only balanced but also more sinusoidal, as shown in Figs. 19(c) and (d). These results 
TABLE IV

Load-Voltage Unbalanced Factor and Loao-Voltage THD

\begin{tabular}{lcccc}
\hline \hline Load Type & $G_{\text {PR_1st }}$ & $G_{\text {PR__rd }}$ & UBF & THD \\
\hline \multirow{3}{*}{ Balanced } & $\times$ & $\times$ & 0 & $6.0 \% / 6.0 \% / 6.0 \%$ \\
Loads & $\sqrt{ }$ & $\times$ & 0 & $6.0 \% / 6.0 \% / 6.0 \%$ \\
& $\sqrt{ }$ & $\mathrm{S} 1$ & 0 & $0.9 \% / 0.9 \% / 0.9 \%$ \\
& $\sqrt{ }$ & $\mathrm{S} 2$ & 0 & $0.9 \% / 0.9 \% / 0.9 \%$ \\
\hline \multirow{3}{*}{ Unbalanced } & $\times$ & $\times$ & $31 \%$ & $5.5 \% / 3.1 \% / 7.4 \%$ \\
Loads & $\sqrt{ }$ & $\times$ & $1 \%$ & $5.9 \% / 5.5 \% / 6.4 \%$ \\
& $\sqrt{ }$ & $\mathrm{S} 2$ & $0.6 \%$ & $0.9 \% / 0.9 \% / 1.0 \%$ \\
& $\sqrt{ }$ & $\mathrm{S} 1$ & $0.6 \%$ & $0.9 \% / 0.9 \% / 1.0 \%$ \\
\hline \hline
\end{tabular}

validate the role of $G_{\mathrm{PR} \_1 s t}(s)$ and $G_{\mathrm{PR} \_3 \mathrm{rd}}(s)$ in improving the voltage quality.

\section{CONCLUSION}

The 3P4W inverter can supply unbalanced loads but needs to afford larger filter inductors because of the neutral wire. In this paper, a neutral inductor is proposed to insert in the neutral wire for saving the total filter inductances in the $3 \mathrm{P} 4 \mathrm{~W} 3 \mathrm{~L}$ inverter. Design methodologies are presented for designing the filter inductors and the neutral inductor, indicating that the insertion of the neutral inductor can benefit the size and volume reduction for the filter inductors by at least $25 \%$. For having high quality load voltages, a resonant controller, with the resonant frequency at $f_{\mathrm{o}}$, is added into the zero-sequence voltage loop for balancing load voltages; concurrently, the other resonant controller, with the resonant frequency at $3 f_{\text {o }}$, is inserted into the zero-sequence voltage (or neutral current) loop for mitigating the voltage distortion. Finally, experimental results are shown to verify the feasibility of all proposed work.

\section{REFERENCES}

[1] J. Rodriguez, J. Lai, and F. Peng, "Multilevel inverters: A survey of topologies, controls and applications," in IEEE Transactions on Industrial Electronics, vol. 49, no. 4, pp. 724-738, Aug. 2002.

[2] A. Nabae, I. Takahashi, and H. Akagi, "A new neutral-point-clamped PWM inverter," in IEEE Transactions on Industry Applications, vol. IA17, no. 5, pp. 518-523, Sept. 1981.

[3] K. Wang, Z. Zheng, L. Xu, and Y. Li, "A generalized carrier-overlapped PWM methodology for neutral-point-clamped multilevel converters," in IEEE Transactions on Power Electronics, vol. 35, no. 9, pp. 9095-9106, Sept. 2020.

[4] M. Schweizer and J. W. Kolar, "Design and implementation of a highly efficient three-level T-type converter for low-voltage applications," in IEEE Transactions on Power Electronics, vol. 28, no. 2, pp. 899-907, Feb. 2013.

[5] R. Teichmann and S. Bernet, "A comparison of three-level converters versus two-level converters for low-voltage drives, traction, and utility applications," in IEEE Transactions on Industry Applications, vol. 41, no. 3, pp. 855-865, May 2005.

[6] S. K. Mondal, J. O. P. Pinto, and B. K. Bose, "A neural-network-based space-vector PWM controller for a three-level voltage-fed inverter induction motor drive," in IEEE Transactions on Industry Applications, vol. 38, no. 3, pp. 660-669, May-Jun. 2002.

[7] A. Deshpande, Y. Chen, B. Narayanasamy, Z. Yuan, C. Chen, and F. Luo, "Design of a high-efficiency, high specific-power three-level T-type power electronics building block for aircraft electric-propulsion drives,' in IEEE Journal of Emerging and Selected Topics in Power Electronics, vol. 8, no. 1, pp. 407-416, Mar. 2020.

[8] A. Choudhury, P. Pillay, and S. S. Williamson, "Comparative analysis between two-level and three-level dc/ac electric vehicle traction inverters using a novel dc-link voltage balancing algorithm," in IEEE Journal of Emerging and Selected Topics in Power Electronics, vol. 2, no. 3, pp. 529-540, Sept. 2014.

[9] A. Anthon, Z. Zhang, M. A. E. Anderson, D. G. Holmes, B. McGrath, and C. A. Teixerira, "The benefits of SiC MOSFETs in a T-type inverter for grid-tie applications," in IEEE Transactions on Power Electronics, vol. 32, no. 4, pp. 2808-2821, Apr. 2017.

[10] J. H. Kim and S. K. Sul, "A carrier-based PWM method for three-phase four-leg voltage source converters," in IEEE Transactions on Power Electronics, vol. 19, no. 1, pp. 66-75, Jan. 2004.

[11] J. Chen, L. Diao, L. Wang, H. Du, and Z. Liu, "Distributed auxiliary inverter of urban rail train-The voltage and current control strategy under complicated load condition," in IEEE Transactions on Power Electronics, vol. 31, no. 2, pp. 1745-1756, Feb. 2016.

[12] Z. Lin, X. Ruan, W. Zhao, H. Liu, and P. Rao, "Optimized design of the neutral inductor and filter inductors in three-phase four-wire inverter with split dc-link capacitors," in IEEE Transactions on Power Electronics, vol. 34, no. 1, pp. 247-262, Jan. 2019.

[13] Z. Liu, J. Liu, and J. Li, "Modeling, analysis, and mitigation of load neutral point voltage for three-phase four-leg inverter," in IEEE Transactions on Industrial Electronics, vol. 60, no. 5, pp. 2010-2021, May 2013.

[14] S. Bifaretti, A. Lidozzi, L. Solero, and F. Crescimbini, "Modulation with sinusoidal third-harmonic injection for active split dc-bus four-leg inverters," in IEEE Transactions on Power Electronics, vol. 31, no. 9, pp. 6226-6236, Sept. 2016.

[15] D. Holmes and T. Lipo, Pulse Width Modulations for Power Converters: Principles and Practice. New York, NY, USA: Wiley, 2003.

[16] J. Pou, J. Zaragoza, S. Ceballos, M. Saeedifard, and D. Boroyevich, "A carrier-based PWM strategy with zero-sequence voltage injection for a three-level neutral-point-clamped converter," in IEEE Transactions on Power Electronics, vol. 27, no. 2, pp. 642-651, Feb. 2012.

[17] M. A. Perales, M. M. Prats, R. Portillo, J. L. Mora, and L. G. Franquelo, "Three-dimensional space vector modulation for four-leg inverters using natural coordinates," in Proceedings of 2004 IEEE International Symposium on Industrial Electronics, 2004, pp. 1129-1134.

[18] K. Wang, Z. Zheng, L. Xu, and Y. Li, "Neutral-point voltage balancing method for five-level NPC inverters based on carrier-overlapped PWM," in IEEE Transactions on Power Electronics, vol. 36, no. 2, pp. 14281440, Feb. 2021.

[19] C. Wang and Y. Li, "Analysis and calculation of zero-sequence voltage considering neutral-point potential balancing in three-level NPC converters," in IEEE Transactions on Industrial Electronics, vol. 57, no. 7, pp. 2262-2271, Jul. 2010.

[20] K. Wang, Y. Li, Z. Zheng, and L. Xu, "Voltage balancing and fluctuationsuppression methods of floating capacitors in a new modular multilevel converter," in IEEE Transactions on Industrial Electronics, vol. 60, no. 5, pp. 1943-1954, May 2013.

[21] X. Chen, X. Ruan, D. Yang, W. Zhao, and L. Jia, "Injected grid current quality improvement for voltage-controlled grid-connected inverter," in IEEE Transactions on Power Electronics, vol. 33, no. 2, pp. 1247-1258, Feb. 2018.

[22] L. Zhang and X. Ruan, "Control schemes for reducing the second harmonic current in two-stage single-phase converter: An overview from dc-bus port-impedance characteristic," in IEEE Transactions on Power Electronics, vol. 34, no. 10, pp. 10341-10358, Oct. 2019.

[23] L. Zhang, X. Ruan, and X. Ren, "Second-harmonic current reduction for two-stage single-phase inverter with boost-derived front-end converter: Control schemes and design considerations," in IEEE Transactions on Power Electronics, vol. 33, no. 7, pp. 6361-6378, Jul. 2018.

[24] L. Zhang, X. Ruan, and X. Ren, "Second-harmonic current reduction and dynamic performance improvement in the two-stage inverters: An output impedance perspective," in IEEE Transactions on Industrial Electronics, vol. 62, no. 1, pp. 394-404, Jan. 2015.

[25] L. Zhang, X. Ren, and X. Ruan, "A bandpass filter incorporated into the 
inductor current feedback path for improving dynamic performance of the front-end dc-dc converter in two-stage inverter," in IEEE Transactions on Industrial Electronics, vol. 61, no. 5, pp. 2316-2325, May 2014.

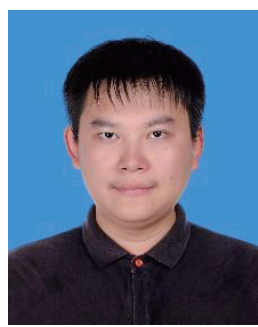

Li Zhang received the B.S. and Ph.D. degrees in electrical engineering from Nanjing University of Aeronautics and Astronautics (NUAA), Nanjing, China, in 2011 and 2017, respectively.

From Aug. 2017 to Jun. 2019, he was a Research Associate with the Center for Ultra-wide-area Resilient Electric Energy Transmission Networks (CURENT), University of Tennessee, Knoxville, TN, USA. Since Jul. 2019, he is a Research Fellow with Energy Research Institute, Nanyang Technological University, Singapore. He has authored or co-authored more than 40 technical papers in top journals and conference proceedings. His research interests include dc-dc conversion, single-phase power conversion, $\mathrm{SiC}$ and GaN power conversion, and renewable energy generation systems.

Dr. Zhang was recognized as a Distinguished Reviewer for the IEEE Transactions on Industrial Electronics in 2019. He was a Topic Chair for IEEE Energy Conversion Congress and Exposition (ECCE) in 2019 and 2020. $\mathrm{He}$ is currently an Associate Editor for the IEEE Transactions on Industrial Electronics.

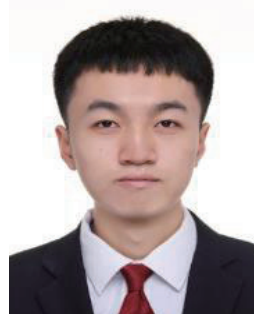

Haoxin Yang received the B.S. degree in electrical engineering from Wuhan University, Wuhan, China, in 2018 and the M.S. degree in power engineering from Nanyang Technological University, Singapore, in 2020, respectively.

$\mathrm{He}$ is currently a research engineer at Energy Research Institute, Nanyang Technological University, Singapore. His research interests include modeling, stability analysis, and control of distributed generation in more-electronics power systems.

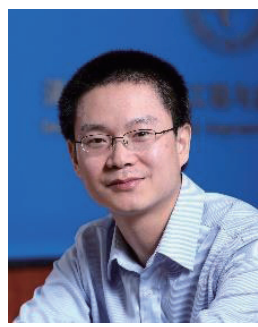

Kui Wang received the B.S. and Ph.D. degrees in Electrical Engineering from the Department of Electrical Engineering, Tsinghua University, Beijing, China, in 2006 and 2011, respectively.

From Sep. 2018 to Aug. 2019, he was a Visiting Scholar with the Center for Ultra-wide-area Resilient Electric Energy Transmission Networks (CURENT), University of Tennessee, Knoxville, TN, USA. He is currently an Assistant Researcher with the Department of Electrical Engineering, Tsinghua University. His research interests include topology and control of multilevel converters, renewable energy generation and wide band-gap semiconductor applications.

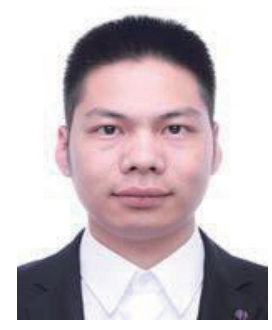

Yalei Yuan received the B.S. degree in Automation from Changchun Institute of Technology, Changchun, in 2013 and the M.S. degree in control engineering in 2017 from the China University of Mining and Technology, Xuzhou, China, where he is currently working toward the Ph.D. degree in electrical engineering.

From Sep. 2019 to Sep. 2020, he was a visiting student at Energy Research Institute, Nanyang Technological University, Singapore. His current research interests include power quality, PV system, energy storage, and multilevel converter.

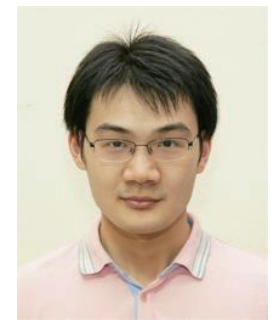

Yi Tang received the B.S. degree in electrical engineering from Wuhan University, Wuhan, China, in 2007 and the M.S. and Ph.D. degrees from the School of Electrical and Electronic Engineering, Nanyang Technological University, Singapore, in 2008 and 2011, respectively.

From 2011 to 2013, he was a Senior Application Engineer with Infineon Technologies Asia Pacific, Singapore. From 2013 to 2015, he was a Postdoctoral Research Fellow with Aalborg University, Aalborg, Denmark. Since March 2015, he has been with Nanyang Technological University, Singapore, where he is currently an Associate Professor. He is the Cluster Director of the Advanced Power Electronics Research Program at the Energy Research Institute, Nanyang Technological University, Singapore.

Dr. Tang was a recipient of the Infineon Top Inventor Award in 2012, the Early Career Teaching Excellence Award in 2017, the Best Associate Editor Award for IEEE Journal of Emerging and Selected Topics in Power Electronics in 2018, the Outstanding Reviewer for IEEE Transactions on Power Electronics in 2019, and four IEEE Prize Paper Awards. He is an Associate Editor for the IEEE Transactions on Power Electronics and the IEEE Journal of Emerging and Selected Topics in Power Electronics.

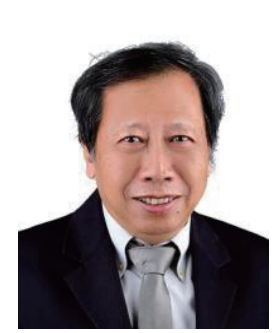

Wai Kuan Loh received his B.S. (Hon), M.S. and $\mathrm{Ph} . \mathrm{D}$. in electrical engineering from University of Manchester Institute of Science and Technology, (UMIST), UK. He worked in industries on motor and drives, industrial automation and renewable energy for more than 20 years. He is now a Senior Scientist with Energy Research Institute, Nanyang Technological University, Singapore, working on power converters for renewable energy, energy storage system and wireless power transfer.

Dr. Loh is Committee Member of the local Industry Applications \& Power Electronics Society Chapter in Singapore. 